\title{
Exploring Perceptions of Barriers, Facilitators and Motivators to Physical Activity among Female Bariatric Patients
}

\author{
Anastasia Dikareva \\ Kinesiology and Physical Education Department \\ McGill University, Montreal \\ June 2013

\begin{abstract}
A thesis submitted
to McGill University in partial fulfillment

of the requirements of the degree of Master of Science

in the Department of Kinesiology and Physical Education

in the Faculty of Education
\end{abstract} \\ (C) Anastasia Dikareva, 2013
}




\section{Abstract}

Canadian women are twice as likely to be severely obese compared to men, are more likely to be physically inactive, and comprise the majority of patients undergoing bariatric treatment for severe obesity. Physical activity (PA) is one of the strongest predictors of successful long-term weight management and is a recommended adjunct to bariatric surgery. However, patients often do not increase levels of PA following surgery and physical inactivity among severely obese women remains poorly understood. Twelve women (mean age $47 \pm 9$ years), who had undergone bariatric surgery in the last two years, were interviewed to explore perceptions of barriers and facilitators to PA. Thematic analysis resulted in development of three key, interrelated themes: the physical body, appraisal of the physical and social self, and the exercise environment. Barriers to PA included weight-restricted mobility, side effects of surgery, body dissatisfaction, compromised psychological health, competing responsibilities, a lack of exercise selfefficacy and social support, reduced access to accommodating facilities, lack of exercise knowledge, as well as northern climate. Participants reported post-surgical weight loss, weight and health maintenance, enjoyment, body image, supportive active relationships, as well as access to accommodating facilities and exercise knowledge as facilitators and motivators for adoption and maintenance of PA. Suggested appropriate PA counselling strategies and programming for healthcare providers and exercise professionals working with this unique population are discussed.

Keywords: physical inactivity; women; severe obesity; weight loss surgery 


\section{Abstract in French}

Les femmes canadiennes ont deux fois plus de chance de souffrir d'obésité morbide en comparaison aux hommes et elles constituent la majorité des patients devant subir une chirurgie bariatrique. L'activité physique (AP) est un des indices les plus important pour une gestion adéquate et long terme du poids et devrait être employée comme complément à la chirurgie bariatrique. Toutefois, les femmes n'augmentent souvent pas leur niveau d'AP suite à une chirurgie bariatrique. L'inaction physique parmi les femmes obèses est un phénomène mal compris. Douze femmes (âge moyen de $47 \pm 9$ ans) qui ont subi une chirurgie bariatrique dans les deux dernières années ont été interviewées pour étudier leur perception à propos des obstacles et des facilitateurs de l'activité physique. Une analyse thématique a résulté dans le développement de trois thèmes : physique, psychosocial et structurel, s'informant et se renforçant mutuellement. Les femmes ont discuté du fait que les barrières physiques de l'activité physique sont le poids restreignant la mobilité, la réduction d'énergie et les effets secondaires de la chirurgie. Les participantes ont également parlé des obstacles psychosociaux suivants : l'insatisfaction au niveau corporel, le manque d'auto-efficacité, le manque de soutien social, le manque de motivation ainsi que la fragilité du bien-être psychologique. Les barrières structurelles comprenaient quant à elles un manque d'installation et d'équipement adapté pour les obèses, un manque de soutien au niveau de l'information et le climat nordique. Nos résultats aident les professionnels de la santé à comprendre quelques défis des femmes souffrant d'obésité morbide qui veulent un traitement de chirurgie bariatrique en adoptant et maintenant simultanément un style de vie physiquement actif. Des stratégies efficaces d'AP et de mise en place de programmes pour ce type spécifique de patients doivent toucher simultanément les trois thèmes clés d'obstacles compte tenu de leur interaction complexe et de leur impact sur le comportement de l'individu par rapport à l'AP.

Mots clés : exercice, femme, problèmes de santé, obésité, perte de poids opération 


\section{Acknowledgements}

I would like to sincerely thank the following individuals without whom the completion of my Master's thesis would not have been possible:

\section{Dr. Ross Andersen}

First and foremost, I would like to thank my supervisor, Dr. Ross Andersen for his support, guidance and expertise that have allowed me to grow academically, professionally and personally over the last year.

\section{Dr. William Harvey and Dr. Susan Bartlett}

I would also like to thank my committee members; Dr. William Harvey and Dr. Susan Bartlett for generously offering their invaluable expertise, insight, and time in helping me complete this work.

\section{The Health and Fitness Promotion Lab}

To all of my dearest lab members, thank you for your support, help in transcribing interviews, hours of wonderful company, for laughing with me and occasionally even at me. May all of our paths continue to cross! I would like to especially acknowledge Tamara Carver and Hannah Lemke for being certifiably awesome and for their enduring support, knowledge, insight, and inspiration. 


\section{Present and former colleagues}

A special thanks to my current and former departmental colleagues: Dr. Jessica Ruglis, Eileen Leduc, Samantha Taran, Eva Pila, Mike Cicchillitti, and the CHAMPS lab who contributed their time, experience and support in helping me complete various phases of this work. I am forever indebted to you.

\section{The participants}

A sincere thank you to the 12 incredible women who volunteered their time and personal experiences to this study. I am humbled to have been invited into your lives to hear some of your personal and intimate stories. This work could not have been possible without your courage and openness in sharing your experiences.

\section{My family}

To mom and Iris, the two women who relentlessly encourage and inspire me to carve my own path towards my dreams; who comfort me in moments of frustration and despair; and who celebrate with me in moments of joy—thank you. And of course, a deep, heartfelt thank you to my brother, grandparents and dearest friends for their unwavering support, patience, love, and great laughs. You all mean the world to me! 
Table of Contents

Abstract.......................................................................................................................... ii

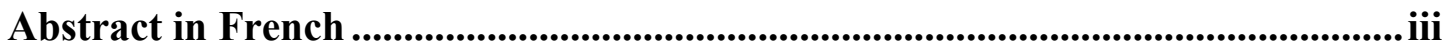

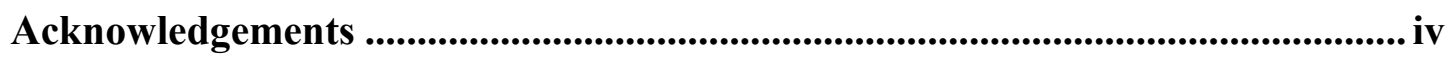

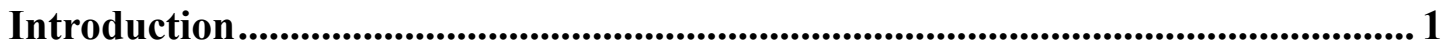

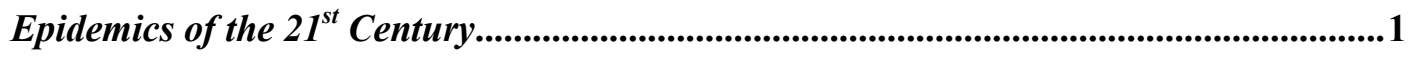

Treatment of Obesity and the Impact of Physical Activity ...................................................3

Physical Activity as Prehabilitation ..............................................................................................6

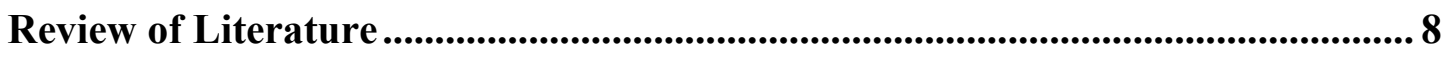

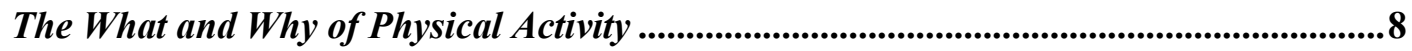

Social and Cognitive Barriers and Facilitators .........................................................11

Excess Weight as a Barrier ................................................................................................................17

Pain, Health Concerns, and Fatigue as Barriers .....................................................................20

Environmental and Structural Barriers and Facilitators ............................................23

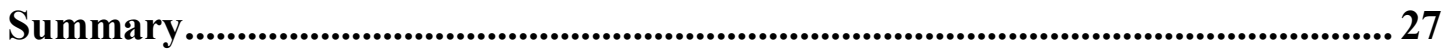

References ........................................................................................................... 30

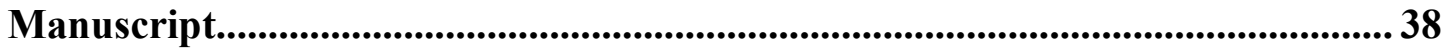

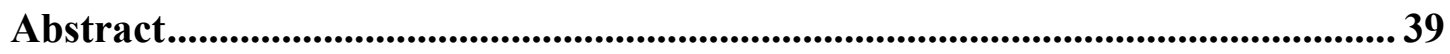

Introduction ............................................................................................................................... 40

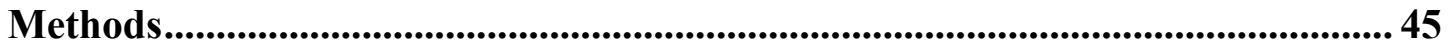

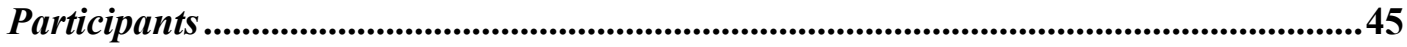

Data Gathering ..................................................................................................................................46

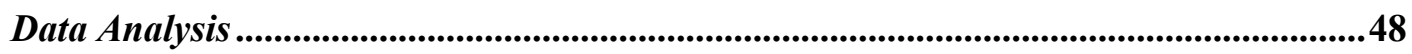

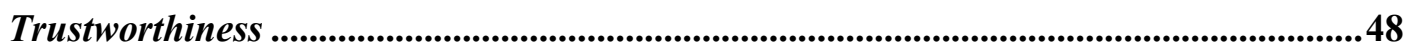

Interview Findings ...................................................................................................... 49

Thematic Analysis.......................................................................................50

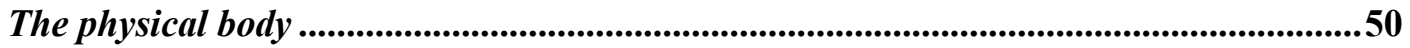

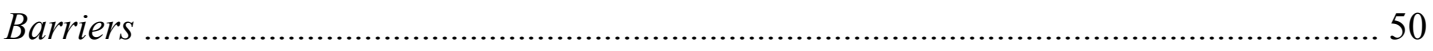

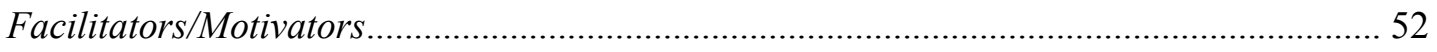

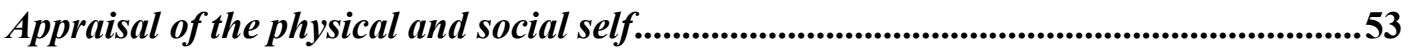

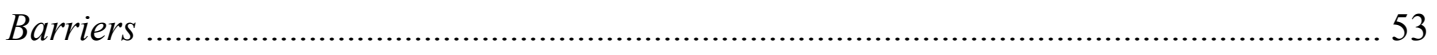

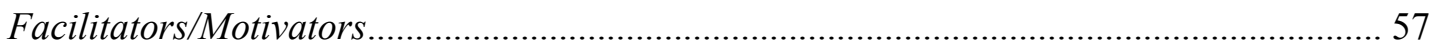

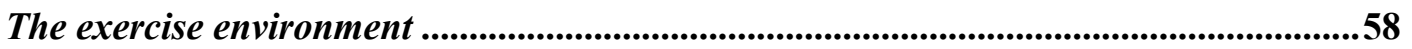

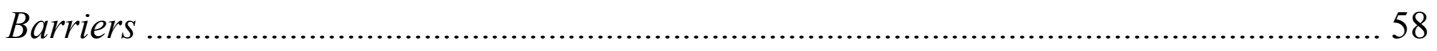

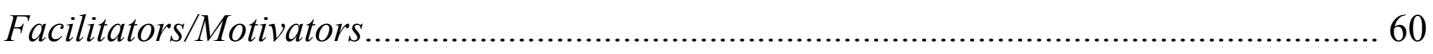




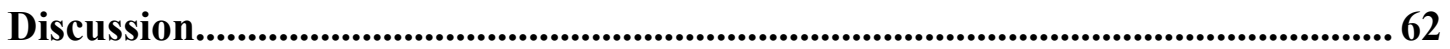

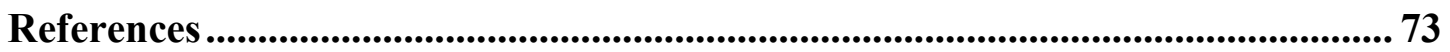

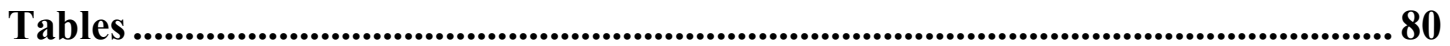

Table 1. Selected participant characteristics. ...................................................................8

Table 2. Participant IWQOL-Lite questionnaire scores presented as percentiles. ...........81

Table 3. Prevalence of main themes and sub-themes (categories) among participants. 82

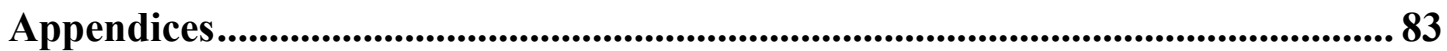

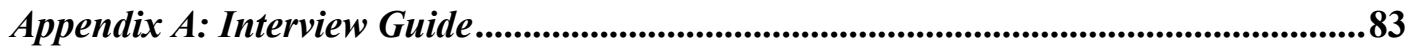

Appendix B: Sample Recruiting Poster ............................................................................85

Appendix C: Informed Consent .......................................................................................................86

Appendix D: International Physical Activity Questionnaire- Short ..................................91

Appendix E: Impact of Weight on Quality of Life- Lite Questionnaire ...........................94 


\section{Introduction}

\section{Epidemics of the $21^{\text {st }}$ Century}

Obesity, operationally defined as a body mass index $(\mathrm{BMI}) \geq 30 \mathrm{~kg} / \mathrm{m}^{2}$, is a complex chronic condition that has reached epidemic proportions sparking intense public health concern in North America and worldwide (Report of a WHO consultation 2000, Caballero 2007). Overweight and obesity are highly associated with increased cardiovascular and all-cause mortality. Currently, $24.1 \%$ of Canadians, $34.4 \%$ of Americans, and upwards of $20 \%$ of Europeans are obese, with an exponentially growing proportion of adults with severe (Class III) obesity (BMI $\geq 40 \mathrm{~kg} / \mathrm{m}^{2}$ ) (Müller-Riemenschneider et al. 2008, Flegal et al. 2010, Shields et al. 2011) Among Canadian women, the prevalence of obesity is $23.9 \%$ and, they are two times more likely to be severely obese compared to men (Jokovic et al. 2006).

Physical activity (PA) is a modifiable risk factor for both obesity and cardiovascular disease. Habitual leisure time PA has been shown to reduce all-cause mortality both in men and women (Andersen et al. 2000). Moreover, regular exercise and cardiorespiratory fitness significantly reduce the risk of mortality and morbidity among normal weight $\left(\mathrm{BMI}=18.5-24.9 \mathrm{~kg} / \mathrm{m}^{2}\right)$ as well as overweight individuals $\left(\mathrm{BMI}=25-29.9 \mathrm{~kg} / \mathrm{m}^{2}\right)$, in a dose dependent fashion (Blair 1993). Various health associations such as the American College of Sports Medicine (ACSM) and Canadian Society for Exercise Physiology (CSEP) recommend that adults aged 18-65 accumulate at least 150 minutes of moderate-to-vigorous intensity aerobic physical activity (MVPA) per week to promote and maintain health (Garber et al. 2011, 
Tremblay et al. 2011). Unfortunately, majority of adults in North America are physically inactive.

The most recent Canadian Health Measures Survey (CHMS) accelerometer data indicate that only $17 \%$ of Canadian men and $14 \%$ of women are meeting PA guidelines. Approximately 53\% of Canadian adults attain only 30 minutes of moderate-to-vigorous physical activity (MVPA) on one or two days per week; a stark contrast to the $52 \%$ of adults who self-report being 'at least moderately active' in their leisure time (Colley et al. 2011). In the US, more than half of the adult population is insufficiently active with over a quarter of adults reporting no leisuretime PA at all (Haskell et al. 2007). Such trends are not limited to North America; only $22 \%$ of Australian adults and $31 \%$ of adults in European Union countries report regularly exercising at moderate intensity (Sjöström et al. 2006 ,"Physical Activity in Australia: A Snapshot, 2007-08”2011).

According to the CHMS, obese men and women attain approximately 19 and 13 minutes of MVPA per day, respectively (Colley et al. 2011). Compared to men, Canadian women are more likely to be physically inactive across all age groups and become progressively more inactive with increasing age and BMI (Bryan and Walsh 200, Tudor-Locke et al. 2010).

As such, obesity and physical inactivity are two independent risk factors for development of chronic conditions such as high blood pressure, coronary heart disease, stroke and diabetes. Moreover, excess weight and inactivity negatively influence musculoskeletal health and thereby, compromise physical function (Jakicic 
and Davis 2011). The associated co-morbidities manifest into significant mental, physical and economic burdens. Treatment of obesity-related conditions are estimated to cost between $.7 \%$ and $2.8 \%$ of total health care expenditures, depending on the country (Withrow and Alter 2011). In fact, obese individuals who are physically inactive, or completely sedentary, incur significantly greater health care costs than obese individuals who are moderately or highly physically active (Wang et al. 2004). Therefore, strategies that will help obese adults, specifically women, improve longterm health outcomes by reducing excess weight and maintaining weight loss by adopting and maintaing a physically active lifestyle represent a public health priority.

\section{Treatment of Obesity and the Impact of Physical Activity}

To date, various treatment modalities have been developed to combat obesity: antiobesity pharmacotherapy (James et al. 2000), reduced calorie and low-fat diets (Katan 2009), exercise interventions (Donnelly et al. 2000), as well as various behavioural modification strategies (Douketis et al. 2005). However, such treatment options have revealed limited success in long-term weight maintenance and control. Bariatric (weight loss) surgery is an increasingly popular and cost-effective treatment that results in rapid loss of body weight with lower long-term mortality risks than other forms of medical obesity management. Bariatric surgery is considered to be a last resort treatment for severely obese individuals, at increased risk for comorbidities, who have been unsuccessful at achieving permanent weight loss through non-surgical means (Padwal 2005). The vast majority of patients who seek bariatric 
surgery are women; of the 1107 bariatric surgeries performed across five Canadian provinces in 2003, 85\% of patients were women (Jokovic et al. 2006).

The disproportionate amount of women seeking bariatric surgery lends itself to the strong social stigma assigned to obese women in reflection of pervasive gender-differentiated cultural norms that promote a standard of thinness as the ideal female body shape (Fredrickson and Roberts 1997, Bookwala and Boyar 2008). Obese women are more likely to experience prejudice and discrimination; have negative attributes such as 'lazy', 'self-indulgent', and 'undisciplined' ascribed to them; and suffer mistreatment due to their weight by a stranger (Carr and Friedman 2005). Weight stigmatization reduces psychological well-being, whereby a greater BMI is highly associated with poorer psychological well-being among women, but not men, even when accounting for sociodemographic characteristics (Bookwala and Boyar 2008). Reduced psychological well-being reduces self-efficacy and motivation which in turn may sabotage long-term adoption of health behaviours such as PA (Napolitano et al. 2011).

Despite drastic initial reductions in weight $(35 \%-80 \%$ of baseline body weight) observed after bariatric surgery, a significant number of patients begin to regain weight within one to two years after surgery (Christou et al.2006). In fact, a high proportion of individuals struggle to maintain at least $5 \%$ of their initial weight loss ten years post-surgery (Sarwer et al. 2011). Regular exercise is a cornerstone of weight loss management, and an active lifestyle is one of the strongest predictors of 
long-term weight maintenance among individuals who have lost significant amounts of body weight (Andersen et al. 2005).

The National Weight Control Registry (NWCR), a longitudinal, observational study of individuals successful at long-term weight loss maintenance, demonstrated that $89 \%$ of individuals who successfully maintained their initial weight loss (a minimum of 30 pounds for at least a year), reported modifying and continuously monitoring both diet and PA. In fact, very few individuals successfully maintained weight loss with diet alone (Wing and Hill 2001). Regular PA has also been positively associated with post-operative weight loss following bariatric surgery, especially among previously inactive patients who begin exercising following surgery (Livhits et al. 2010, Jacobi et al. 2011). On the other hand, physical inactivity has demonstrated adverse effects on weight loss following gastric bypass surgery (Hatoum et al. 2009). Unfortunately, PA monitoring studies report that a majority of bariatric patients fail to increase their PA levels post-surgery (Bond et al. 2010).

A recent cluster analysis of 2,152 NWCR participants identified unique subgroups of participants with distinct weight control experiences, attitudes and strategies towards weight loss maintenance. Specifically, Ogden et al. (2012) identified the "struggling" cluster of NWCR participants (26.9\% of sample) who not only experienced significantly greater difficulty in maintaining weight, but were also predominantly female (83.1\%), more likely to weight cycle, and had the highest maximum lifetime BMI of $44.7 \mathrm{~kg} / \mathrm{m}^{2}$. This cluster was also trying to maintain the greatest weight loss with an average of 100.5 pounds below maximum weight. 
Interestingly, the struggling cluster was the most likely to report using PA for weight control, yet expended fewer calories in the form of PA $(2,492 \mathrm{kcal} / \mathrm{week})$ compared to the "normal' and 'immediately successful' clusters, who were both successful at long-term weight maintenance and expended an average of 2,853 kcal/week and 2,660 kcal/week, respectively (Ogden et al. 2012). Evidently, obese women not only struggle to adhere to endorsed PA guidelines, but also have difficulty maintaining excess weight loss. Therefore, it is of critical importance to develop sustainable, personalized strategies that will facilitate adoption of, and adherence to, a physically active lifestyle following bariatric surgery.

\section{Physical Activity as Prehabilitation}

Emerging evidence also suggests that pre-operative exercise (prehabilitation) may augment pre-operative functional capacity, which in turn may improve post-surgical recovery and reduce the likelihood of surgical complications. Mayo et al. (2011) observed meaningful changes in functional walking capacity (assessed using the SixMinute Walk Test) in a trial of colorectal surgery patients who were randomized to a prehabilitative exercise program consisting of stationary cycling plus weight training, compared to a control group that received a recommendation to increase walking. Despite a lack of significant difference between treatment groups and low patient adherence to the prehabilitative program, $33 \%$ of patients exhibited an improvement in pre-operative physical function. Those who improved pre-operatively were significantly more likely to recover their baseline walking capacity after surgery compared to those who did not demonstrate a change, or deteriorated, in pre-surgical 
functional capacity. Moreover, individuals who experienced an increase in presurgical functional capacity also reported improved perceived health, vitality and increased peak exercise capacity. However, women were less likely to improve in this prehabilitative program, possibly due to poor adherence (Mayo et al. 2011).

Most recently, Li et al. (2012) demonstrated significant improvements in postsurgical outcomes among colorectal cancer patients in a trimodal prehabilitative program consisting of moderate intensity exercise, nutritional counselling, protein supplementation and anxiety reduction counselling. In this instance, the prehabilitative group exhibited significantly higher post-operative functional walking capacity and quicker recovery from surgery compared to the control group that received standard surgical care (Li et al. 2012). Similarly, implementation of preoperative exercise regimens, or a mere increase in daily PA, may aid in patient recovery and improvement in post-operative functional capacity following bariatric surgery.

In order to maximize bariatric surgery and life-long health outcomes, the obesity treatment paradigm must shift its focus from excess weight loss itself, to long-term weight loss management that emphasizes a physically active lifestyle. Considering that an overwhelming portion of severely obese individuals are physically inactive, particularly women, it is imperative to understand why severely obese adults struggle to meet the recommended PA guidelines. Physical inactivity among severely obese women is a multifaceted phenomenon that is not well understood. Currently, there is a dearth of qualitative literature that explores 
perceptions of barriers and facilitators to PA among severely obese women.

Qualitative inquiry can aid in development of effective clinical PA interventions and counselling techniques in an attempt to forge lifelong PA habits within the short-term transition period from pre to post bariatric surgery.

Hence, this study adopts qualitative methodology to explore barriers and facilitators associated with engaging in regular PA among women, who have recently undergone bariatric surgery at McGill University Health Center (MUHC) in Montreal, Quebec, Canada. It is expected that findings from this exploratory study will: a) provide a deeper understanding of challenges hindering adoption of PA for severely obese women; b) assist health care professionals in counselling bariatric patients and prescribing effective PA strategies that will facilitate long-term weight loss maintenance, and c) provide evidence-based details to design a tailored exercise program that can be sustainable in clinical practice.

\section{Review of Literature}

\section{The What and Why of Physical Activity}

PA is a complex health behaviour defined as any bodily movement that results in expenditure of energy through contraction of skeletal muscles. Leisure-time PA (LTPA) and occupational PA are two subtypes of PA. LTPA can be further subdivided into sports, conditioning exercises, and household activities (e.g., yard work, cleaning, etc.). On the other hand, exercise is defined as planned, structured bodily movements that are performed with the objective to achieve and maintain 
various health parameters such as cardiorespiratory fitness (Caspersen, Powell, \& Christenson, 1985). These definitions have various implications in public health promotion, as the perceived benefits of each type of activity may not be equivocal, even though both are positively associated with health benefits. However, for the purpose of this discussion these two terms will be used interchangeably.

The physical and mental benefits of aerobic exercise are well established. Regular PA improves lipoprotein profiles, body composition and musculoskeletal health; enhances insulin sensitivity; and has been shown to attenuate bone loss, blood pressure and stress, among other physiological and psychological benefits (Garber et al. 2011). As previously stated, health associations such as ACSM and CSEP currently recommend that normal weight adults aged 18-65 accumulate at least 150 minutes of MVPA per week to promote and maintain health (Garber et al. 2011, Tremblay et al. 2011). Recommendations can be met by accumulating physical activity in 30-60 minute bouts of moderate-intensity exercise, such as brisk walking, three to five times per week; or in 20-60 minute bouts of vigorous-intensity exercise like jogging on two to three days per week. Additionally, these guidelines can be met by performing any combination of moderate and vigorous intensity activity in the form of structured exercise or free living PA such as walking or cycling for commuting ("Physical Activity and Public Health" 2007).

In order to elicit clinically significant reductions in body weight (approximately $5-10 \%$ of baseline weight) for obese individuals, ACSM suggests that 200 to 300 minutes of MVPA per week may be required since weight loss and 
PA have a dose-dependent relationship (Donnelly et al. 2009). For bariatric patients, the American Society of Metabolic and Bariatric Surgery recommends 20 minutes of mild PA per day, 3 to 4 times per week, prior to surgery to reduce risk of surgical complications and enhance postoperative recovery. Postoperatively, patients are encouraged to gradually increase their PA levels to meet the general guidelines currently endorsed by ACSM and CSEP for a healthful lifestyle (King and Bond 2013). However, it may be particularly daunting for moderately and severely obese individuals to achieve and maintain such high levels of PA. Considering the current population trends in physical inactivity among obese individuals, even pre- and postoperative PA recommendations may be too excessive for some bariatric patients.

In order to effectively address physical inactivity in this unique population, it is pertinent to understand the challenges as well as the facilitators that operate during PA adoption and adherence among severely obese individuals, specifically among women who have received bariatric treatment. Despite a lack of literature exploring inactivity among severely obese women, it is possible to draw from the knowledge of previous quantitative and qualitative works that have explored barriers and facilitators among normal weight, overweight, moderately obese $\left(\mathrm{BMI}=30-35 \mathrm{~kg} / \mathrm{m}^{2}\right)$ individuals as well as other patient populations. Therefore, the following sections will outline and explore the four most prevalent categories of barriers and facilitators to PA among severely obese women through discussion of factors affecting PA identified to date among normal weight, overweight and moderately obese individuals. 


\section{Social and Cognitive Barriers and Facilitators}

Traditional approaches to PA intervention design are often grounded in theoretical perspectives of behaviour change, such as the Self-Determination Theory, that hinge on individual control over health promoting behaviours like regular PA (Kirk and Colquhoun 1989, King et al. 2002). Though no theory exclusively predicts behaviour change, these frameworks operate under the assumption that the innate motivation towards health is largely governed by social and cognitive regulatory processes (Epstein 1998). As such, literature surrounding physical inactivity has frequently focused on identifying individual regulatory processes that function during adoption and maintenance of PA.

Self-efficacy, defined as the confidence to maintain a task-specific behaviour in spite of salient hurdles, has a long-standing recognition as a key concept in health behaviour change specifically in the context of weight loss and PA (Strecher et al. 1986). An early longitudinal investigation by Sallis and group (1992) elucidated some of the most prominent individual predictors of exercise adoption and maintenance. Exercise self-efficacy and history of PA were the most significant predictors of PA adoption among both men and women, possibly because the latter tends reinforce the former. PA tracking data support this notion. Activity patterns in young adulthood (20-25 years of age) are moderately associated with PA patterns at 32-41 years of age, suggesting that PA habits developed earlier on in life may inform PA behaviour and cultivate self-efficacy in the long term (Herman et al. 2009) for both women and men. 
Sallis et al. (1992) also demonstrated a positive association of perceived benefits of PA with exercise adoption among initially sedentary men, while family support, friend support and having positive exercise role models increased likelihood of PA adoption among sedentary women. With respect to exercise maintenance, selfefficacy was the strongest positive predictor among initially active men, while exercise adherence among initially active women could only be predicted (inversely) by age (Sallis et al. 1992). These longitudinal data served as an early indication that cognitive and social predictors of PA vary not only between genders but also between phases of PA adoption and individual exercising status. Carr and Friedman (2006) later demonstrated that obese and severely obese individuals report higher levels of strain in social and familial relationships and less emotional support from friends compared to normal weight individuals, especially if they were overweight in early adulthood (Carr and Friedman 2006). Given the predictive power of social support in PA adoption among women, strained social relationships may impede adoption of this behaviour among obese women.

A community-based PA intervention among predominantly Caucasian, sedentary, overweight women conducted by Williams et al. (2008) revealed that selfefficacy, social support, enjoyment, and agreement with PA associated benefits were factors highly correlated with both PA adoption and maintenance. In fact, high selfefficacy increased odds of participation in regular PA by $139 \%$, making it the strongest predictor of exercise maintenance observed by the investigators (Williams et al. 2008). These findings parallel those previously established by Gallagher et al. 
(2005), whereby PA adoption among moderately obese women over a 6-month behavioural weight loss trial was positively correlated with self-efficacy, social support, and a positive value judgement on PA. Though this intervention aimed to modify levels of PA as well as energy intake among participants, those who attained $>10 \%$ weight loss reported significantly higher exercise self- efficacy and enlisting social support more frequently when engaging in PA compared to the group that achieved $<5 \%$ weight loss (Gallagher et al.2006).

Napolitano et al. (2011) demonstrated that the nature and frequency of social and cognitive barriers to PA tend to operate as a function of BMI among women, which negatively impacts the likelihood of exercise adoption. In this women-only PA intervention trial, overweight and obese women reported more barriers, such as 'feeling self-conscious when I do activities', 'I am too overweight' and 'lack of self discipline/willpower', compared to normal weight women. Among overweight women, those who reported fewer barriers to PA achieved an average of 42.3 minutes/week more PA than those with more barriers. Among obese women, these effects were even more pronounced, whereby women who reported fewer barriers achieved 70 minutes/week of exercise more than those in the high barrier group.

In contrast, normal weight women were not only significantly more likely to take up and adhere to an exercise program, but also reported barriers that were structural in nature, such as bad weather, indicating that they were in the later stages of change in behaviour modification (Napolitano et al. 2011). The Trans-theoretical Model of Behaviour Change posits that behavioural processes are engaged towards 
the later stages of behaviour modification, whereby barriers such as time and weather are more likely to prevail than a lack of willpower or motivation, making adoption of new health behaviours such as PA easier (Prochaska and Velicer 1997). When Rye et al. (2009) investigated barriers to PA according to these stages of change among rural, low-income, overweight and obese women, it was found that a lack of willpower and support, opposed to a lack of time, were indeed the dominant challenges cited (Rye et al. 2009).

Similar findings have been found in other patient populations. A recent study investigating PA barriers among breast and prostate cancer survivors observed that salient cognitive barriers such a lack of willpower were in fact associated with lower levels of PA for both genders, though more so for women compared to men. The most commonly cited barrier, 'no willpower', in this patient group resulted in 39.5 and 18.7 minutes less of PA achieved per week for women and men, respectively. Breast cancer survivors in this study also reported family obligations, feeling selfconscious, and lack of exercise partners as barriers to PA significantly more often than men (Ottenbacher et al. 2011).

While quantitative studies are effective for establishing relationships between possible predictors of participation in PA based on statistical association, such means are insufficient for capturing the contextual interplay between determinants of a physically active lifestyle. Qualitative methodology offers more promising implications for health behaviour research by providing a deeper understanding of reasons for physical inactivity among moderately obese and severely obese 
individuals through exploratory inquiry of their subjective experiences (Denzin and Lincoln 2005). In other words, how do individuals make sense of a phenomenon like PA or exercise in a given context?

A focus group study of 13 self-identified obese individuals (nine women) revealed a lack of self-efficacy and knowledge to begin creating a work-out plan, which collectively dampened motivation to take up PA (Suggs et al. 2010). Moreover, even though participants recognized the importance of PA for health, they acknowledge exercise as 'hard work', which in turn reinforced low self-esteem and feelings of discomfort when exercising next to someone who was perceived as athletic. When asked to describe preferences for PA related communication, interpersonal forms of interaction from physicians were cited as the trustworthiest mode of communication (Suggs et al. 2010). Igelstrom et al. (2012) also found that majority of obese patients (47\% women) with obstructive sleep apnea had negative previous experiences with exercise, or no experience at all, which hindered their belief in being able to take up regular PA. These participants stressed the importance of health care support as a facilitator to PA. However, for this patient group, health care support content varied from individual coaching to group activities in a supervised environment (Igelström et al. 2012). These findings are important as they not only highlight the pervasiveness of low exercise self-efficacy among obese individuals, as a consequence of previous experiences, but also provide evidence for limited success of current PA promotion campaigns and the urgent need for personally relevant PA and weight loss counselling strategies. 
In fact, Huang et al. (2004) established that of 210 overweight and obese patients interviewed at a primary care hospital, $79 \%$ of patients recalled being counselled to lose weight, yet only $28 \%$ of patients were given specific strategies to facilitate their weight loss and only $10 \%$ of these patients reported receiving specific counselling to increase PA. Physician focus groups in the same setting revealed that some of the barriers resident-physicians face in providing weight loss counselling include pessimism about patients' desire to lose weight and feeling ill-informed of the most appropriate clinical practice for weight loss counselling (Huang et al. 2004). Understanding barriers to PA among obese individuals can begin to clarify healthcare providers' misperceptions of their patients' struggles with weight loss that encompass a lack of social support, positive experiences with exercise, and exercise-based knowledge. These PA-related struggles may in turn, decrease self-esteem in exercise situations, and reduce PA self-efficacy and motivation.

Moreover, compromised mental health may pose a challenge to being physical active for severely obese women. Galper et al. (2006) demonstrated an inverse, doseresponse relationship between depressive symptoms and PA among adults in the Aerobics Centre Longitudinal Study (Galper et al.2006). And Morrato et al. (2007) has shown that depression is one of the strongest correlates with physical inactivity among adults living with, or at risk of developing diabetes (Morrato et al. 2007). With respect to bariatric patients, approximately $25 \%$ to $30 \%$ of individuals seeking bariatric surgery report clinically significant symptoms of depression and over $50 \%$ of patients report a history of mood or anxiety disorders (Wadden et al. 2007). Given 
that exercise motivation is closely related to affective states like depression, reduced mental health may negatively impact obese individuals' ability to maintain a physically active lifestyle (Frederick et al. 1996).

\section{Excess Weight as a Barrier}

Compelling evidence exists to indicate that difficulty in initiating and maintaining a physically active lifestyle for obese women can be partially explained by the physical and psychosocial effects of excess weight. Ekkekakis and Lind (2006) have shown that sedentary, overweight women exercise at a higher relative intensity than their normal weight counterparts and report more laborious, unpleasant experiences with exercise at self-selected and imposed intensities (Ekkekakis and Lind 2006). Wingo et al. (2011) conducted a series of focus groups on a group of obese adults ( $76 \%$ women) and reported a prevailing belief among participants that was described as a heightened response to exercise compared to normal weight individuals. An exaggerated physiological response in turn, increased their safety concerns and feelings of frustration when unable to keep up in a group setting, ultimately dampening participant motivation to continue an exercise regimen (Wingo et al. 2011). A phenomenological study by Wiklund et al. (2011) also reported that severely obese individuals (50\% women) awaiting gastric bypass surgery felt physically hindered by a heavier body that required constant self-management in order to minimize joint pain that became exacerbated with activity. Thus, these patients cited weight loss as a prerequisite to becoming physically active. This group also emphasized the added social stress when forced to consider how to navigate their 
bodies in exercise situations such as fitting in an exercise apparatus or tolerating public criticism while appearing in a bathing suit (Wiklund et al. 2010). To our knowledge, this is the only qualitative study to have explored bariatric surgery patients' experiences with PA.

Literature also suggests that perception of being 'too fat' to exercise (overweight perception) may hinder adoption of a physically active lifestyle. An urban population fitness survey of 2,298 Australian adults revealed that $9.3 \%$ of respondents with a BMI $>25 \mathrm{~kg} / \mathrm{m}^{2}$ felt that they were 'too fat' to increase their PA levels. Women were three times more likely than men to cite excess weight as a barrier to PA, and a significantly higher proportion of obese individuals cited this barrier compared to overweight and normal weight adults (Ball et al. 2000). This weight related barrier was also strongly associated with feelings of embarrassment and a lack of motivation for both men and women. Moreover, of those who reported feeling 'too fat', $16.7 \%$ of men and $14.5 \%$ of women also felt that their 'health was not good enough to exercise', though this barrier was independent of feeling 'too fat' (Ball et al. 2000). In the PA promotion trial conducted by Napolitano et al. (2011), only obese women endorsed feeling too overweight as a barrier to PA at baseline and one year post-intervention compared to normal weight and overweight women (Napolitano et al. 2011).

Other findings support the potentiating effect of overweight perception on perpetuating physical inactivity. Atlantis et al. (2008) compared prevalence of LTPA between overweight and obese adults who perceived themselves to be at an 
acceptable weight or as overweight. In agreement with current public health data, excess weight was strongly associated with high levels of physical inactivity among men and women. Overweight perception among overweight and obese men resulted in less PA participation, whereas no perception and LTPA level interaction was observed among men who perceived themselves at an acceptable weight. Such findings suggest that perception of excess weight, as a barrier to PA, may be just as important as physical weight itself. In contrast to men, no association could be established for overweight perception and likelihood of meeting recommended PA guidelines among overweight women. Overweight and obese women achieved less LTPA than normal weight women, as well as overweight and obese men, irrespective of their weight perception (Atlantis et al. 2008). Vartanian and Shaprow (2008) have shown that weight stigmatizing experience may foster PA avoidance behaviours, irrespective of BMI and body image dissatisfaction, among female undergraduate collegiate students (Vartanian and Shaprow 2008). As previously mentioned, obese women are more likely to experience weight discrimination and prejudice compared to obese men (Carr and Friedman 2005). Therefore, it is possible that the psychosocial effects of weight stigmatization, not overweight perception, may hinder PA adoption and maintenance among obese women.

Collectively, these findings elucidate the psychosocial complexities experienced by obese women as individuals living with excess weight. Ultimately, these lived experiences inform, and are in part formed by, various social and cognitive barriers to PA such as decreased self-efficacy, exercise motivation, and 
depression. Decreased self-efficacy and lack of motivation for exercise may in turn exacerbate perception of pain and foster pain-avoidance behaviours.

\section{Pain, Health Concerns, and Fatigue as Barriers}

Pain and disability are frequently cited barriers to PA among numerous patient populations. Studies among patients with chronic back pain and musculoskeletal disorders demonstrate that activity-related pain contributes to fear-avoidance behaviour, which negatively impact self-efficacy and thus, participation in PA (Geisser et al. 2000, Damsgard et al. 2010). Since many obese individuals frequently suffer from concomitant conditions such as osteoarthritis and joint pain that limit mobility and promote deconditioning, pain and disability can become substantial deterrents to PA participation for obese women (Nevitt and Lane 1999). In fact, one of the most prominent positive changes revealed among post-gastric bypass surgery patients is the resolution of mobility- limiting co-morbidities that prevent patients from engaging in PA (Bocchieri et al. 2002).

Qualitative and quantitative evidence support the prevalence of joint and chest pain, as well as safety concerns related to pain, surrounding PA participation among obese individuals. Wingo et al. (2011) observed that almost all focus group participants associated exercise symptom severity such as chest pain with severity of their physiological response. Additionally, a predisposed risk to a cardiovascular event heightened the perception of a 'normal' physical response to exercise, whereby participants unanimously stressed the importance of medical clearance and supervised exercise by a health professional (Wingo et al. 2011). Furthermore, members 
revealed that the expectation of local and global body pain post-exercise often discouraged future strenuous exercise sessions. Similarly, clinical observations by Vincent et al. (2010) observed an elevated fear of movement and decreased PA among severely obese individuals with knee pain, compared to their non-obese counterparts, despite reporting lower knee-pain ratings (Vincent et al. 2010). Given these findings, it is possible that fear of movement and pain underlies physical inactivity and obesity.

A qualitative case study by Wathne (2011) demonstrated that PA-avoidance behaviours and somatic adaptations to limited movement develop early in life for obese individuals. Wathne (2011) described movement difficulties faced by a 12-year old girl due to her altered posture and redistributed centre of gravity as a consequence of carrying excess upper body weight. Even at a young age, 'Berit' complained of lower back pain and repeatedly refused to perform bending and twisting movements, even when participating in activities of her choice (Wathne 2011). Thus, the physical limitations endured by obese individuals, and the compensatory somatic and cognitive adaptations developed throughout a lifetime in response to living with excess weight, may hinder obese women's ability to engage in a physically active lifestyle.

Declining levels of activity (or prolonged inactivity) may lead to a spiral of negative health consequences including: reduced physical function; more pain and discomfort with subsequent bouts of PA; and reduced motivation for continued activity, which over time reduces exercise self-efficacy and fosters pain-avoidance 
behaviours. This series of events assumes a cycle where PA associated fearavoidance behaviours perpetuate obesity and physical inactivity. The Self-Efficacy Theory may help explain the reported lack of self-efficacy. According to the theory, perceived exercise capability is affected by past performances, vicarious experiences, social persuasion, and physiological/affective states (Bandura 1999). With respect to self-efficacy among obese women, negative weight-related physiological states such as joint pain and previous negative PA experiences may be facilitating the decrease in perceived exercise capability.

A PA-promotion trial by Rimmer et al. (2010) also identified pain and health concerns as the most pervasive barriers encountered by obese African American women with mobility disabilities. Implementing a motivational interviewing approach, trained exercise physiologists helped participants navigate these challenges with education, reassurance, and individually tailored suggestions that emphasized activities of daily living featuring household chores and leisure walking as well as structured exercise. Post-intervention, the average exercise time increased from $<6$ minutes/day to 27 minutes/day while total PA time increased from 26 minutes/day to 89 minutes/day. Such individually tailored PA counselling programs suggest that acknowledgment of persisting pain and health related concerns among obese women and education by trained healthcare professionals can act as a facilitator to PA in this population (Rimmer et al. 2010).

Literature also suggests that exercise exhaustion and fatigue may prevent obese women from engaging in PA. Obese individuals utilize a greater proportion of 
their maximal oxygen capacity $\left(\mathrm{VO}_{2} \mathrm{max}\right)$ during PA compared to normal weight individuals; using approximately $50 \%$ of $\mathrm{VO}_{2} \max$ compared to $30 \%$ of $\mathrm{VO}_{2} \mathrm{max}$ among normal weight individuals during PA. Therefore, even relatively low-intensity tasks like walking may produce excessive fatigue (Poirier and Després 2001). Mattsson et al. (1997) previously quantified the oxygen costs of walking among obese and normal weight women. As predicted, obese women walked slower at selfselected speeds, had a higher oxygen consumption, and reported greater perceived exhaustion Borg scale ratings compared to normal weight women (Mattsson et al. 1997). Ultimately, discomfort and fatigue resulting from PA exceeding individual physical capacity diminishes energy reserves to complete other daily non-PA related tasks and discourages future bouts of PA among obese individuals (Stankov et al. 2012).

\section{Environmental and Structural Barriers and Facilitators}

The assertion that individuals are their own agents of change and moral reproof has dominated the field of study in physical activity and health promotion research (Smith-Dijulio et al. 2010). However, the relative influence of social and built environments believed to encourage sedentary activity that perpetuate physical inactivity and promote excess weight gain, has recently garnered support in understanding barriers to PA (Bauman et al. 2004). Sedentary occupational demands are on the rise and have been shown to be positively associated with obesity among men and women (Choi et al. 2010). Moreover, a number of physical environmental characteristics are postulated to create an obesogenic environment by affecting levels 
of PA: urban sprawl, access to local parks/green space, fast food outlet/convenience store density, neighbourhood walkability, public transportation accessibility, and access to recreation facilities.

Urban sprawl, characterized by low residential density areas, impacts levels of PA by decreasing opportunities for walking and cycling, both for leisure and transportation, and encouraging car use. Areas of high residential density tend to be more connected with identifiable neighbourhood centers, which promote walkability and PA (Frank et al. 2006). An ecological study by Ewing et al. (2003) demonstrated that individuals living in more compact U.S. counties such as New York boroughs report more minutes of walking than those who live in more sprawling counties such as Geauga Country in Cleveland, Ohio. Consequently, residents of more sprawling areas have greater BMIs than individuals residing in urban areas (Ewing et al.2003). Such findings are not limited to North America, a study of metropolitan Sydney, Australia revealed similar results; those living in low residential density neighbourhoods achieve less PA and weigh more than individuals residing in metropolitan centers (Garden and Jalaludin 2009).

A mixed-methods study by Bove and Olson (2006) among rural, low-income women revealed that obese informants were twice as likely to cite transportation difficulties compared to normal weight informants. Residing outside of population centres, with fewer opportunities to be active, limited women to sedentary activities at home. In response to feelings of isolation and boredom, a consequence of being unable to leave home, respondents cited engaging in 'emotional eating' as a method 
of coping (Bove and Olson 2006). In addition to living in neighbourhoods with decreased walkability, obese women may be particularly discouraged from outside walking due to increased instability on slippery and uneven surfaces, especially in northern climates (Poirier and Després 2001).

Research has shown that objectively measured environmental characteristics influencing adoption of a physically active lifestyle operate differently for men and women. Multilevel analysis and obesity in a large Canadian city by Prince et al. (2012) demonstrated that, for women, LTPA was highly associated with proximity to park areas; however, park area was also positively associated with overweight/obesity, as was convenience store and fast-food outlet density. For men, only crime rates were associated (negatively) both with LTPA and overweight/obesity (Prince et al. 2012). Interestingly, Prince et al. (2012) did not find any significant associations between facility variables (indoor/outdoor recreation facilities, bike/walk paths, etc.) and levels of LTPA. The contradictory relationship between park area, LTPA, and obesity among women may be a reflection of unreliable self-report PA data, the lack of specificity in defining 'park area' or its intended use, or simply a non-linear relationship between obesity and park access. Nevertheless, these data point to a more complex gender-mediated interaction of social and physical environmental factors with LTPA and obesity than previously believed.

Such incongruent findings are not entirely surprising; objective measures of environmental characteristics deemed conducive for PA do not always align with 
individual perception of the same environmental supports. Kirtland et al. (2003) found little agreement between reported environmental landmarks (e.g., sidewalks, recreation facilities, water ways, etc.) in a community survey and landmarks indicated by geographic information systems for the neighbourhoods in question. According to the authors, individuals tend to overestimate distances to PA community supports, possibly as a result of their preference for habitual routes and lifestyle behaviours, leading them to perceive their environment non-conducive for habitual PA (Kirtland et al. 2003). Giles-Corti and Donovan (2002) also established that the physical environment's influence on habitual PA is, indeed, secondary to individual and social determinants of PA. While access to facilities determined whether or not they were used by respondents of a community survey, psychosocial determinants such as subjective norms, attitude towards PA, and social support governed whether or not endorsed levels of PA were being achieved (Giles-Corti and Donovan 2002). Similarly, an exploratory study of motives for active commuting during relocation in Cambridge, United Kingdom established that individuals' decision to adopt a physically active mode of transportation to and from work was primarily determined by convenience, speed, and reliability of their mode of transportation (walking or cycling) (Jones and Ogilvie 2012).

In addition to the built environment, lack of time, due to competing occupational and familial obligations, may prevent obese women from engaging in regular PA. Lack of personal time is a salient, well-documented barrier to PA in various population groups, especially among low-income women (Brownson et al. 
2001). Obesity among women is associated with a distinct income disadvantage whereby obese women earn consistently less than normal weight women and obese men, regardless of their level of education (Sarlio-Lähteenkorva et al. 2004).

Subsequently, financial strain not only decreases access to cost-based facilities and opportunities for PA, but also necessitates dedication of a greater portion of personal time for moneymaking and caregiving endeavours (Chang et al. 2008).

Though the social and built environments as determinants of PA have gained popularity in PA-promotion research, there remains a lack of qualitative literature that documents environmental and structural barriers to PA among obese women. Further qualitative inquiry may help understand the specific aspects of the built environment affecting PA among obese women and how these environmental factors interact with individual barriers such as weight-restricted mobility, lack of social support, or reduced mental health.

\section{Summary}

A significant proportion of bariatric patients struggle to maintain their weight loss following surgery. Regular PA is imperative for successful long-term weight loss maintenance following bariatric treatment. Unfortunately, severely obese women are more likely to be physically inactive across all ages and BMI categories compared to their male counterparts. Women also comprise the majority of the bariatric patient population. Physical inactivity among severely obese women is a multifaceted phenomenon that is not well understood. Currently, there is a dearth of qualitative 
literature that explores perceptions of barriers and facilitators to adopting and maintaining regular PA among severely obese women. Qualitative inquiry can help shape development of effective clinical PA interventions and counselling techniques that will forge lifelong PA habits within the short-term transition period from pre to post bariatric surgery.

This exploratory study was comprised of 12 purposefully sampled women who underwent weight loss surgery within the last two years at a bariatric clinic in the McGill University Health Centre in Montreal, Quebec, Canada. To our knowledge, this is the first study to explore perceptions of barriers, facilitators, and motivators to adopting and maintaining a physically active lifestyle among severely obese women who underwent surgical weight loss treatment. Study findings highlight three key themes of barriers, facilitators, and motivators to PA: the physical body, appraisal of the physical and social self, and the exercise environment. These results should help healthcare and exercise professionals working with severely obese women in developing tailored PA counselling strategies that address barriers and leverage facilitators and motivators for PA in a given social and physical environment. Additionally, our findings offer insight to obese women's experiences with PA, their relationships with their bodies, and struggles with compromised psychological health. Future studies should explore this phenomenon among obese men specifically. Furthermore, it is of interest to explore perceptions of barriers and facilitators to PA among women, and men, who have surpassed the two-year peak weight loss period post-bariatric surgery, as some of the body image transformations 
that reportedly affected PA levels among participants may have been completed, thereby, possibly creating a new set of barriers and motivators for PA. 


\section{References}

Andersen, L. B., Schnohr, P., Schroll, M., \& Hein, H. O. (2000). All-Cause Mortality Associated With Physical Activity During Leisure Time, Work, Sports, and Cycling to Work. Arch Intern Med, 160(11), 1621-1628. doi: 10.1001/archinte.160.11.1621

Andersen, R. E., Bartlett, S. J., Beamer, B. A., Kim, K. S., Franckowiak, S. C., \& Walston, J. D. (2005). Lipid Profile And Glucose Tolerance After Novel Exercise Interventions For Weight Loss And Weight Maintenance: 1750 11:15 AM - 11:30 AM. Medicine \& Science in Sports \& Exercise, 37(5), S338.

Atlantis, E., Barnes, E. H., \& Ball, K. (2008). Weight status and perception barriers to healthy physical activity and diet behavior. [Research Support, Non-U.S. Gov't]. International Journal of Obesity, 32(2), 343-352.

Ball, K., Crawford, D., \& Owen, N. (2000). Too fat to exercise? Obesity as a barrier to physical activity. Aust N Z J Public Health, 24(3), 331-333.

Bandura, A. (1999). Self-efficacy: Toward a unifying theory of behavioral change.

Bauman, A. E., Reis, R. S., Sallis, J. F., Wells, J. C., Loos, R. J. F., \& Martin, B. W. Correlates of physical activity: why are some people physically active and others not? The Lancet, 380(9838), 258-271. doi: 10.1016/s01406736(12)60735-1

Blair, S. N. (1993). Evidence for success of exercise in weight loss and control. Ann Intern Med, $119(7 \mathrm{Pt} 2), 702-706$.

Bocchieri, L. E., Meana, M., \& Fisher, B. L. (2002). Perceived psychosocial outcomes of gastric bypass surgery: a qualitative study. Obes Surg, 12(6), 781-788. doi: 10.1381/096089202320995556

Bond, D. S., Jakicic, J. M., Unick, J. L., Vithiananthan, S., Pohl, D., Roye, G. D., . . . Wing, R. R. (2010). Pre- to postoperative physical activity changes in bariatric surgery patients: self report vs. objective measures. Obesity (Silver Spring), 18(12), 2395-2397. doi: 10.1038/oby.2010.88

Bookwala, J., \& Boyar, J. (2008). GENDER, EXCESSIVE BODY WEIGHT, AND PSYCHOLOGICAL WELL-BEING IN ADULTHOOD. Psychology of Women Quarterly, 32(2), 188-195. doi: 10.1111/j.1471-6402.2008.00423.x

Bove, C. F., \& Olson, C. M. (2006). Obesity in low-income rural women: qualitative insights about physical activity and eating patterns. Women Health, 44(1), 5778. doi: 10.1300/J013v44n01_04

Brownson, R. C., Baker, E. A., Housemann, R. A., Brennan, L. K., \& Bacak, S. J. (2001). Environmental and policy determinants of physical activity in the United States. Journal Information, 91(12).

Bryan, S., \& Walsh, P. (2004). Physical Activity and Obesity in Canadian Women. BMC Womens Health, 4 Suppl 1, S6. doi: 10.1186/1472-6874-4-s1-s6 
Caballero, B. (2007). The Global Epidemic of Obesity: An Overview. Epidemiologic Reviews, 29(1), 1-5. doi: 10.1093/epirev/mxm012

Carr, D., \& Friedman, M. A. (2005). Is obesity stigmatizing? Body weight, perceived discrimination, and psychological well-being in the United States. J Health Soc Behav, 46(3), 244-259.

Carr, D., \& Friedman, M. A. (2006). Body weight and the quality of interpersonal relationships. Social Psychology Quarterly, 69(2), 127-149.

Caspersen, C. J., Powell, K. E., \& Christenson, G. M. (1985). Physical activity, exercise, and physical fitness: definitions and distinctions for health-related research. Public Health Rep, 100(2), 126-131.

Chang, M. W., Nitzke, S., Guilford, E., Adair, C. H., \& Hazard, D. L. (2008). Motivators and barriers to healthful eating and physical activity among lowincome overweight and obese mothers. Journal of the American Dietetic Association, 108(6), 1023-1028.

Choi, B., Schnall, P. L., Yang, H., Dobson, M., Landsbergis, P., Israel, L., . . Baker, D. (2010). Sedentary work, low physical job demand, and obesity in US workers. Am J Ind Med, 53(11), 1088-1101. doi: 10.1002/ajim.20886

Christou, N. V., Look, D., \& Maclean, L. D. (2006). Weight gain after short- and long-limb gastric bypass in patients followed for longer than 10 years. Ann Surg, 244(5), 734-740. doi: 10.1097/01.sla.0000217592.04061.d5

Colley, R. C., Garriguet, D., Janssen, I., Craig, C. L., Clarke, J., \& Tremblay, M. S. (2011). Physical activity of Canadian adults: accelerometer results from the 2007 to 2009 Canadian Health Measures Survey. Health Rep, 22(1), 7-14.

Damsgard, E., Thrane, G., Anke, A., Fors, T., \& Roe, C. (2010). Activity-related pain in patients with chronic musculoskeletal disorders. Disabil Rehabil, 32(17), 1428-1437. doi: $10.3109 / 09638280903567877$

Denzin, N. K., \& Lincoln, Y. S. (2005). The Sage Handbook of Qualitative Research 3rd edition. Thousand Oaks: Sage Publications.

Donnelly, J. E., Blair, S. N., Jakicic, J. M., Manore, M. M., Rankin, J. W., \& Smith, B. K. (2009). American College of Sports Medicine Position Stand. Appropriate physical activity intervention strategies for weight loss and prevention of weight regain for adults. Med Sci Sports Exerc, 41(2), 459-471. doi: 10.1249/MSS.0b013e3181949333

Donnelly, J. E., Jacobsen, D. J., Heelan, K. S., Seip, R., \& Smith, S. (2000). The effects of 18 months of intermittent vs. continuous exercise on aerobic capacity, body weight and composition, and metabolic fitness in previously sedentary, moderately obese females. International Journal of Obesity \& Related Metabolic Disorders: Journal of the International Association for the Study of Obesity, 24(5), 566-572.

Douketis, J. D., Macie, C., Thabane, L., \& Williamson, D. F. (2005). Systematic review of long-term weight loss studies in obese adults: clinical significance and applicability to clinical practice. Int J Obes (Lond), 29(10), 1153-1167. doi: 10.1038/sj.ijo.0802982 
Ekkekakis, P., \& Lind, E. (2006). Exercise does not feel the same when you are overweight: the impact of self-selected and imposed intensity on affect and exertion. Int J Obes (Lond), 30(4), 652-660. doi: 10.1038/sj.ijo.0803052

Epstein, L. H. (1998). Integrating theoretical approaches to promote physical activity. American Journal of Preventive Medicine, 15(4), 257-265.

Ewing, R., Schmid, T., Killingsworth, R., Zlot, A., \& Raudenbush, S. (2003). Relationship between urban sprawl and physical activity, obesity, and morbidity. Am J Health Promot, 18(1), 47-57.

Flegal, K. M., Carroll, M. D., Ogden, C. L., \& Curtin, L. R. (2010). Prevalence and Trends in Obesity Among US Adults, 1999-2008. JAMA: The Journal of the American Medical Association, 303(3), 235-241. doi: 10.1001/jama.2009.2014

Frank, L. D., Andresen, M. A., \& Schmid, T. L. (2004). Obesity relationships with community design, physical activity, and time spent in cars. [Research Support, Non-U.S. Gov't

Research Support, U.S. Gov't, P.H.S.]. American Journal of Preventive Medicine, 27(2), 87-96.

Frank, L. D., Sallis, J. F., Conway, T. L., Chapman, J. E., Saelens, B. E., \& Bachman, W. (2006). Many Pathways from Land Use to Health: Associations between Neighborhood Walkability and Active Transportation, Body Mass Index, and Air Quality. Journal of the American Planning Association, 72(1), 75-87. doi: 10.1080/01944360608976725

Frederick, C. M., Morrison, C., \& Manning, T. (1996). MOTIVATION TO PARTICIPATE, EXERCISE APFECT, AND OUTCOME BEHAVIORS TOWARD PHYSICAL ACTIVITY. Perceptual and Motor Skills, 82(2), 691701. doi: 10.2466/pms.1996.82.2.691

Fredrickson, B. L., \& Roberts, T.-A. (1997). OBJECTIFICATION THEORY. Psychology of Women Quarterly, 21(2), 173-206. doi: 10.1111/j.14716402.1997.tb00108.x

Gallagher, K. I., Jakicic, J. M., Napolitano, M. A., \& Marcus, B. H. (2006).

Psychosocial factors related to physical activity and weight loss in overweight women. Med Sci Sports Exerc, 38(5), 971-980. doi:

10.1249/01.mss.0000218137.25970.c6

Galper, D. I., Trivedi, M. H., Barlow, C. E., Dunn, A. L., \& Kampert, J. B. (2006). Inverse association between physical inactivity and mental health in men and women. Medicine and Science in Sports and Exercise, 38(1), 173.

Garber, C. E., Blissmer, B., Deschenes, M. R., Franklin, B. A., Lamonte, M. J., Lee, I.-M., ... Swain, D. P. (2011). Quantity and Quality of Exercise for Developing and Maintaining Cardiorespiratory, Musculoskeletal, and Neuromotor Fitness in Apparently Healthy Adults: Guidance for Prescribing Exercise. Medicine \& Science in Sports \& Exercise, 43(7), 1334-1359 1310.1249/MSS.1330b1013e318213fefb. 
Garden, F. L., \& Jalaludin, B. B. (2009). Impact of urban sprawl on overweight, obesity, and physical activity in Sydney, Australia. J Urban Health, 86(1), 1930. doi: 10.1007/s11524-008-9332-5

Geisser, M. E., Haig, A. J., \& Theisen, M. E. (2000). Activity Avoidance and Function in Persons with Chronic Back Pain. Journal of Occupational Rehabilitation, 10(3), 215-227. doi: 10.1023/a:1026666403039

Giles-Corti, B., \& Donovan, R. J. (2002). The relative influence of individual, social and physical environment determinants of physical activity. Soc Sci Med, 54(12), 1793-1812.

Haskell, W. L., Lee, I. M., Pate, R. R., Powell, K. E., Blair, S. N., Franklin, B. A., . . Bauman, A. (2007). Physical activity and public health: updated recommendation for adults from the American College of Sports Medicine and the American Heart Association. Circulation, 116(9), 1081-1093. doi: 10.1161/circulationaha.107.185649

Hatoum, I. J., Stein, H. K., Merrifield, B. F., \& Kaplan, L. M. (2009). Capacity for physical activity predicts weight loss after Roux-en-Y gastric bypass. Obesity (Silver Spring), 17(1), 92-99. doi: 10.1038/oby.2008.507

Herman, K. M., Craig, C. L., Gauvin, L., \& Katzmarzyk, P. T. (2009). Tracking of obesity and physical activity from childhood to adulthood: the Physical Activity Longitudinal Study. Int J Pediatr Obes, 4(4), 281-288. doi: 10.3109/17477160802596171

Huang, J., Yu, H., Marin, E., Brock, S., Carden, D., \& Davis, T. (2004). Physicians' weight loss counseling in two public hospital primary care clinics. Acad Med, 79(2), 156-161.

Igelström, H., Martin, C., Emtner, M., Lindberg, E., \& Asenlöf, P. (2012). Physical activity in sleep apnea and obesity-personal incentives, challenges, and facilitators for success. Behavioral sleep medicine, 10(2), 122-137.

Jacobi, D., Ciangura, C., Couet, C., \& Oppert, J. M. (2011). Physical activity and weight loss following bariatric surgery. Obes Rev, 12(5), 366-377. doi: 10.1111/j.1467-789X.2010.00731.x

Jakicic, J. M., \& Davis, K. K. (2011). Obesity and physical activity. Psychiatr Clin North Am, 34(4), 829-840. doi: 10.1016/j.psc.2011.08.009

James, W. P., Astrup, A., Finer, N., Hilsted, J., Kopelman, P., Rossner, S., . . V Van Gaal, L. F. (2000). Effect of sibutramine on weight maintenance after weight loss: a randomised trial. STORM Study Group. Sibutramine Trial of Obesity Reduction and Maintenance. Lancet, 356(9248), 2119-2125.

Jokovic, A., Frood, J., \& Leeb, K. (2006). Bariatric surgery in Canada: obesity rates for Canadian adults are much higher today than in the past; however, rates of bariatric surgery, a treatment for high-risk severely obese individuals, have not risen in parallel. Healthc Policy, 1(2), 64-70.

Jones, C., \& Ogilvie, D. (2012). Motivations for active commuting: a qualitative investigation of the period of home or work relocation. International Journal of Behavioral Nutrition and Physical Activity, 9(1), 109. 
Katan, M. B. (2009). Weight-loss diets for the prevention and treatment of obesity. $N$ Engl J Med, 360(9), 923-925. doi: 10.1056/NEJMe0810291

King, A. C., Stokols, D., Talen, E., Brassington, G. S., \& Killingsworth, R. (2002). Theoretical approaches to the promotion of physical activity: Forging a transdisciplinary paradigm. American Journal of Preventive Medicine, 23(2, Supplement 1), 15-25. doi: 10.1016/s0749-3797(02)00470-1

King, W. C., \& Bond, D. S. (2013). The importance of preoperative and postoperative physical activity counseling in bariatric surgery. Exerc Sport Sci Rev, 41(1), 26-35. doi: 10.1097/JES.0b013e31826444e0

Kirk, D., \& Colquhoun, D. (1989). Healthism and Physical Education. British Journal of Sociology of Education, 10(4), 417-434. doi: 10.1080/0142569890100403

Kirtland, K. A., Porter, D. E., Addy, C. L., Neet, M. J., Williams, J. E., Sharpe, P. A., ... Ainsworth, B. E. (2003). Environmental measures of physical activity supports: Perception versus reality. American Journal of Preventive Medicine, 24(4), 323-331. doi: http://dx.doi.org/10.1016/S0749-3797(03)00021-7

Li, C., Carli, F., Lee, L., Charlebois, P., Stein, B., Liberman, A., . . Feldman, L. (2012). Impact of a trimodal prehabilitation program on functional recovery after colorectal cancer surgery: a pilot study. Surgical Endoscopy, 1-11. doi: 10.1007/s00464-012-2560-5

Livhits, M., Mercado, C., Yermilov, I., Parikh, J. A., Dutson, E., Mehran, A., . . . Gibbons, M. M. (2010). Exercise following bariatric surgery: systematic review. Obes Surg, 20(5), 657-665. doi: 10.1007/s11695-010-0096-0

Mattsson, E., Larsson, U. E., \& Rössner, S. (1997). Is walking for exercise too exhausting for obese women? [Article]. International Journal of Obesity \& Related Metabolic Disorders, 21(5), 380.

Mayo, N. E., Feldman, L., Scott, S., Zavorsky, G., Kim do, J., Charlebois, P., . . . Carli, F. (2011). Impact of preoperative change in physical function on postoperative recovery: argument supporting prehabilitation for colorectal surgery. Surgery, 150(3), 505-514. doi: 10.1016/j.surg.2011.07.045

Morrato, E. H., Hill, J. O., Wyatt, H. R., Ghushchyan, V., \& Sullivan, P. W. (2007). Physical activity in US adults with diabetes and at risk for developing diabetes, 2003. Diabetes Care, 30(2), 203-209.

Müller-Riemenschneider, F., Reinhold, T., Berghöfer, A., \& Willich, S. (2008). Health-economic burden of obesity in Europe. European Journal of Epidemiology, 23(8), 499-509. doi: 10.1007/s10654-008-9239-1

Napolitano, M. A., Papandonatos, G. D., Borradaile, K. E., Whiteley, J. A., \& Marcus, B. H. (2011). Effects of weight status and barriers on physical activity adoption among previously inactive women. Obesity (Silver Spring), 19(11), 2183-2189. doi: 10.1038/oby.2011.87

Nevitt, M. C., \& Lane, N. (1999). Body weight and osteoarthritis. The American Journal of Medicine, 107(6), 632-633. doi: 10.1016/s0002-9343(99)00297-1

Obesity: preventing and managing the global epidemic. Report of a WHO consultation. (2000). World Health Organ Tech Rep Ser, 894, i-xii, 1-253. 
Ogden, L. G., Stroebele, N., Wyatt, H. R., Catenacci, V. A., Peters, J. C., Stuht, J., . . . Hill, J. O. (2012). Cluster analysis of the national weight control registry to identify distinct subgroups maintaining successful weight loss. Obesity.

Ottenbacher, A. J., Day, R. S., Taylor, W. C., Sharma, S. V., Sloane, R., Snyder, D. C., . . Demark-Wahnefried, W. (2011). Exercise among breast and prostate cancer survivors--what are their barriers? J Cancer Surviv, 5(4), 413-419. doi: 10.1007/s11764-011-0184-8

Padwal, R. S. (2005). Characteristics of patients undergoing bariatric surgery in Canada. Obes Res, 13(12), 2052-2054. doi: 10.1038/oby.2005.253

Physical Activity and Public Health. (2007). Circulation, 116(9), 1081-1093. doi: 10.1161/circulationaha.107.185649

Physical Activity in Australia: A Snapshot, 2007-08. (2011). Australian Bureau of Statistics.

Poirier, P., \& Després, J.-P. (2001). EXERCISE IN WEIGHT MANAGEMENT OF OBESITY. Cardiology Clinics, 19(3), 459-470. doi: http://dx.doi.org/10.1016/S0733-8651(05)70229-0

Prince, S. A., Kristjansson, E. A., Russell, K., Billette, J. M., Sawada, M. C., Ali, A., ... Prud'homme, D. (2012). Relationships Between Neighborhoods, Physical Activity, and Obesity: A Multilevel Analysis of a Large Canadian City. Obesity (Silver Spring). doi: 10.1038/oby.2011.392

Prochaska, J. O., \& Velicer, W. F. (1997). The Transtheoretical Model of Health Behavior Change. American Journal of Health Promotion, 12(1), 38-48. doi: 10.4278/0890-1171-12.1.38

Rimmer, J. H., Hsieh, K., Graham, B. C., Gerber, B. S., \& Gray-Stanley, J. A. (2010). Barrier removal in increasing physical activity levels in obese African American women with disabilities. J Womens Health (Larchmt), 19(10), 1869-1876. doi: 10.1089/jwh.2010.1941

Rye, J. A., Rye, S. L., Tessaro, I., \& Coffindaffer, J. (2009). Perceived barriers to physical activity according to stage of change and body mass index in the west virginia wisewoman population. Womens Health Issues, 19(2), 126-134.

Sallis, J. F., Hovell, M. F., \& Richard Hofstetter, C. (1992). Predictors of adoption and maintenance of vigorous physical activity in men and women. Preventive Medicine, 21(2), 237-251. doi: 10.1016/0091-7435(92)90022-a

Sarlio-Lähteenkorva, S., Silventoinen, K., \& Lahelma, E. (2004). Relative weight and income at different levels of socioeconomic status. Journal Information, 94(3).

Sarwer, D. B., Dilks, R. J., \& West-Smith, L. (2011). Dietary intake and eating behavior after bariatric surgery: threats to weight loss maintenance and strategies for success. Surgery for Obesity and Related Diseases, 7(5), 644651. doi: 10.1016/j.soard.2011.06.016

Shields, M., Carroll, M. D., \& Ogden, C. L. (2011). Adult obesity prevalence in Canada and the United States. NCHS Data Brief(56), 1-8.

Sjöström, M., Oja, P., Hagströmer, M., Smith, B., \& Bauman, A. (2006). Healthenhancing physical activity across European Union countries: the 
Eurobarometer study. Journal of Public Health, 14(5), 291-300. doi: 10.1007/s10389-006-0031-y

Smith-Dijulio, K., Windsor, C., \& Anderson, D. (2010). The shaping of midlife women's views of health and health behaviors. Qual Health Res, 20(7), 966976. doi: $10.1177 / 1049732310362985$

Stankov, I., Olds, T., \& Cargo, M. (2012). Overweight and obese adolescents: what turns them off physical activity? International Journal of Behavioral Nutrition and Physical Activity, 9(1), 53.

Strecher, V. J., McEvoy DeVellis, B., Becker, M. H., \& Rosenstock, I. M. (1986). The Role of Self-Efficacy in Achieving Health Behavior Change. Health Education \& Behavior, 13(1), 73-92. doi: 10.1177/109019818601300108

Suggs, L. S., McIntyre, C., \& Cowdery, J. E. (2010). OVERWEIGHT AND OBESE SEDENTARY ADULTS' PHYSICAL ACTIVITY BELIEFS AND PREFERENCES. American Journal of Health Studies, 25(2), 69-77.

Tremblay, M. S., Warburton, D. E., Janssen, I., Paterson, D. H., Latimer, A. E., Rhodes, R. E., ... Duggan, M. (2011). New Canadian physical activity guidelines. Appl Physiol Nutr Metab, 36(1), 36-46; 47-58. doi: 10.1139/h11009

Tudor-Locke, C., Brashear, M. M., Johnson, W. D., \& Katzmarzyk, P. T. (2010). Accelerometer profiles of physical activity and inactivity in normal weight, overweight, and obese U.S. men and women. Int J Behav Nutr Phys Act, 7 , 60. doi: 10.1186/1479-5868-7-60

Vartanian, L. R., \& Shaprow, J. G. (2008). Effects of Weight Stigma on Exercise Motivation and Behavior: A Preliminary Investigation among College-aged Females. Journal of Health Psychology, 13(1), 131-138. doi: $10.1177 / 1359105307084318$

Vincent, H. K., Lamb, K. M., Day, T. I., Tillman, S. M., Vincent, K. R., \& George, S. Z. (2010). Morbid obesity is associated with fear of movement and lower quality of life in patients with knee pain-related diagnoses. $P M R, 2(8), 713-$ 722. doi: $10.1016 /$ j.pmrj.2010.04.027

Wadden, T. A., Sarwer, D. B., Fabricatore, A. N., Jones, L., Stack, R., \& Williams, N. S. (2007). Psychosocial and Behavioral Status of Patients Undergoing Bariatric Surgery: What to Expect Before and After Surgery. Medical Clinics of North America, 91(3), 451-469. doi: http://dx.doi.org/10.1016/j.mcna.2007.01.003

Wang, F., McDonald, T., Champagne, L. J., \& Edington, D. W. (2004). Relationship of body mass index and physical activity to health care costs among employees. J Occup Environ Med, 46(5), 428-436.

Wathne, K. (2011). Movement of large bodies impaired: the double burden of obesity: somatic and semiotic issues. Sport, Education and Society, 16(4), 415-429.

Wiklund, M., Olsen, M. F., \& Willen, C. (2010). Physical activity as viewed by adults with severe obesity, awaiting gastric bypass surgery. Physiother Res Int. doi: 10.1002/pri.497 
Williams, D., Lewis, B., Dunsiger, S., Whiteley, J., Papandonatos, G., Napolitano, M., ... Marcus, B. (2008). Comparing Psychosocial Predictors of Physical Activity Adoption and Maintenance. Annals of Behavioral Medicine, 36(2), 186-194. doi: 10.1007/s12160-008-9054-7

Wing, R. R., \& Hill, J. O. (2001). Successful weight loss maintenance. Annu Rev Nutr, 21, 323-341. doi: 10.1146/annurev.nutr.21.1.323

Wingo, B. C., Evans, R. R., Ard, J. D., Grimley, D. M., Roy, J., Snyder, S. W., . . . Baskin, M. L. (2011). Fear of physical response to exercise among overweight and obese adults. Qualitative Research in Sport, Exercise \& Health, 3(2), 174-192.

Withrow, D., \& Alter, D. A. (2011). The economic burden of obesity worldwide: a systematic review of the direct costs of obesity. Obes Rev, 12(2), 131-141. doi: 10.1111/j.1467-789X.2009.00712.x 


\title{
MANUSCRIPT
}

Submitted to Qualitative Research in Sport, Exercise and Health Exploring Perceptions of Barriers, Facilitators, and Motivators to Physical Activity among Female Bariatric Patients

\author{
A. Dikareva ${ }^{1}$, W. J. Harvey ${ }^{1}$, M. A. Cicchillitti ${ }^{1}$, S. J. Bartlett ${ }^{2}$, R.E. \\ Andersen $^{1}$ \\ ${ }^{I}$ Department of Kinesiology and Physical Education, McGill University, Montreal, \\ Canada, ${ }^{2}$ Department of Medicine, Faculty of Medicine, Mc Gill University, \\ Montreal, Canada
}

\section{Contribution of Authors:}

Primary Author: Anastasia Dikareva

Co-Authors: William J. Harvey, Michael A. Cicchillitti, Susan J. Bartlett, and Ross E. Andersen

The primary author's roles in this study included: recruiting participants, conducting interviews, transcribing interviews, coding the data, conducting the analyses and writing the manuscript under the guidance of the co-authors. Modifications were made in response to the co-authors' feedback. 


\section{Abstract \\ Exploring Perceptions of Barriers, Facilitators, and Motivators to Physical Activity among Female Bariatric Patients}

Canadian women are twice as likely to be severely obese compared to men, are more likely to be physically inactive, and comprise the majority of patients undergoing bariatric treatment for severe obesity. Physical activity (PA) is one of the strongest predictors of successful long-term weight management and is a recommended adjunct to bariatric surgery. However, patients often do not increase levels of PA following surgery and physical inactivity among severely obese women remains poorly understood. Twelve women (mean age $47 \pm 9$ years), who had undergone bariatric surgery in the last two years, were interviewed to explore perceptions of barriers and facilitators to PA. Thematic analysis resulted in development of three key, interrelated themes: the physical body, appraisal of the physical and social self, and the exercise environment. Barriers to PA included weight-restricted mobility, side effects of surgery, body dissatisfaction, compromised psychological health, competing responsibilities, a lack of exercise self-efficacy and social support, reduced access to accommodating facilities, lack of exercise knowledge, as well as northern climate. Participants reported post-surgical weight loss, weight and health maintenance, enjoyment, body image, supportive active relationships, as well as access to accommodating facilities and exercise knowledge as facilitators and motivators for adoption and maintenance of PA. Suggested appropriate PA counselling strategies and programming for healthcare providers and exercise professionals working with this unique population are discussed.

Keywords: physical inactivity; women; severe obesity; weight loss surgery 


\section{Introduction}

The proportion of adults in Canada classified as severely obese (Class III; body mass index $[\mathrm{BMI}] \geq 40 \mathrm{~kg} / \mathrm{m}^{2}$ ) has increased by 400 percent over the last three decades (Katzmarzyk and Mason 2006). Currently, approximately 24 percent of women are obese $\left.(\mathrm{BMI}) \geq 30 \mathrm{~kg} / \mathrm{m}^{2}\right)$ and they are twice as likely to be severely obese compared to men (Shields et al. 2011). ). The burden of treating of obesity-related conditions is not limited to Canada and is estimated to cost between $.7 \%$ and $2.8 \%$ of total health care expenditures, depending on the country (Withrow and Alter 2011).

Concomitant with the rise in prevalence of severe obesity, the number of bariatric (i.e., surgical weight loss) procedures performed across Canada has increased as well (Buchwald and Williams 2004). Surgical weight loss is currently the most effective treatment for severely obese individuals who: (a) are at increased risk for co-morbidities such as type 2 diabetes or osteoarthritis and (b) have been unsuccessful at achieving permanent weight loss through non-surgical means (Karmali et al. 2010). The majority of patients who seek surgical weight loss intervention are women. Women comprised 82 percent of bariatric patients among the 847 surgeries performed across Canada from 2007 - 2008 (excluding the province of Quebec) (Padwal et al. 2012). Unfortunately, a significant number of patients regain weight within one to two years despite drastic reductions in weight initially observed after bariatric surgery. For example, they may regain 35-85 percent of baseline body weight (Christou et al. 2006). In fact, approximately a quarter of 
patients struggle to maintain at least 5 percent of their initial weight loss ten years post-surgery (Sarwer et al. 2011).

Regular physical activity (PA) is among the cornerstones of successful surgical weight management and an active lifestyle is one of the strongest predictors of long-term weight maintenance (Aills et al. 2008, Goodpaster et al. 2010, Jakicic \& Davis 2011). The American Society for Metabolic and Bariatric Surgery, the Obesity Society, and the American Association of Clinical Endocrinologists collectively endorse that bariatric patients achieve at least 30 minutes per day of moderate to vigorous PA following surgery (Mechanick et al. 2008). However, PA monitoring studies suggest that a majority of bariatric patients fail to significantly increase their PA levels post surgery (Bond et al. 2010). For example, Bond and colleagues (2010) gathered accelerometer data to discover only 5 percent of patients met PA guidelines post-surgery.

Compared to men, Canadian women have lower rates of physically activity across all age groups, with rates of inactivity increasing with age and BMI, across both genders (Bryan \& Walsh 2004, Colley et al. 2011, Tudor-Locke et al. 2010). In order to optimize weight loss maintenance and lifelong health outcomes following bariatric surgery, it is important to understand barriers and facilitators that individuals who undergo bariatric surgery may face when adopting and maintaining a physically active lifestyle. Unfortunately, physical inactivity among severely obese women who undergo bariatric treatment is a complex, multifaceted phenomenon that is poorly understood. 
Barriers to PA pertain to various personal, social and environmental challenges that may prevent an individual from adopting and maintaining a physically active lifestyle. Conversely, facilitators, or motivators, to PA encompass personal, social and environmental factors that may help an individual adopt and maintain regular PA. Though barriers, facilitators and motivators to PA have been carefully evaluated and explored among normal weight, overweight and obese adults, little is known about the unique needs of severely obese women, who have undergone bariatric treatment and how these needs may be impacted by bariatric intervention and the dramatic weight loss experienced immediately following surgery.

Studies on overweight and obese individuals suggest that excess weight itself is associated with increased difficulty initiating and maintaining PA, in part, due to negative sensations experienced during exercise. For example, Ekkekakis and Lind (2006) have shown that sedentary, overweight women exercise at a higher relative intensity than their normal weight counterparts. They also reported more laborious, unpleasant experiences with exercise at self-selected and imposed intensities (Ekkekakis and Lind 2006). This perceived rate of exertion might be further pronounced among severely obese women. In focus groups exploring experiences with physical activity, obese individuals (50 percent women) awaiting bariatric surgery, reported feeling physically hindered by a heavier body which required constant self-management of movement in order to minimize joint pain (Wiklund et al. 2010). Participants also reported experiencing significant stress when trying to navigate their bodies in exercise environments such as fitting into exercise 
equipment. Thus, individuals viewed weight loss as a prerequisite to allowing them to become more physically active (Wiklund et al. 2010). While these studies begin to demonstrate challenges to PA reported by overweight and severely obese adults, facilitators and barriers to PA persisting post-bariatric surgery were not systematically explored.

Attitudinal and social factors, such as a lack of exercise self-efficacy and social support, which are well-documented barriers to PA in the general and overweight population, may also negatively affect PA among severely obese women. Gallagher et al. (2006) observed that obese women, who achieved $>10$ percent weight loss in a behavioural weight loss trial, reported significantly higher exercise selfefficacy and enlisted social support more frequently when engaging in PA compared to the group that achieved $<5$ percent weight loss. A lack of exercise knowledge, perceptions that exercise is 'hard work', as well as feelings of discomfort and low self-esteem when exercising next to someone perceived as athletic have also been identified as barriers to PA among obese adults (Suggs et al. 2010). Further research is required to explore how similar attitudinal barriers and facilitators may affect severely obese women receiving bariatric treatment. Exploratory inquiry with this distinct population of people may offer insight into how these factors are informed by various environmental contexts, and obesity-related co-morbidities such as joint pain and sleep apnea.

PA among severely obese women may also be hampered by a lack of exercise knowledge and informational support from healthcare professionals. Among 210 
overweight and obese patients surveyed at a primary care hospital, 79 percent of patients recalled being counselled to lose weight; yet only 28 percent of patients were given specific strategies to facilitate their weight loss (Huang et al. 2004). Moreover, only 10 percent of these patients reported receiving specific medical counselling to increase PA. Physicians in the same hospital described pessimism about patients' desire to lose weight, and a lack of comfort about how to effectively counsel patients to increase PA (Huang et al. 2004). These findings maybe a symptom of negative bias towards obese individuals and inadequate training in tailored PA counselling of obese individuals among health care and exercise professionals (McKenna et al. 1998, Huizinga et al. 2009). A more comprehensive understanding of the barriers and facilitators to PA faced by women undergoing bariatric treatment, would allow for the development of tailored PA counselling techniques that would improve rates of successful adoption and long-term maintenance of a physically active lifestyle, thereby facilitating long-term weight loss maintenance.

Currently, much of what is known about the unique challenges and needs of severely obese individuals when initiating and maintaining regular PA has been collected through the completion of surveys that probe limited PA-related factors. Quantitative studies are effective for establishing relationships between possible predictors of participation in PA based on statistical association. However, such means may not be optimal for promoting a deeper understanding of individual and environmental barriers and facilitators to PA in this group. Qualitative inquiry offers an opportunity to explore in greater depth how various factors, as perceived by 
severely obese women who have undergone bariatric treatment, might serve as barriers or facilitators to PA. To date, almost all of the existing qualitative literature exploring PA among obese adults includes mixed-gender focus group studies of overweight or moderately obese adults and only one qualitative study included men and women awaiting bariatric surgery. This approach may leave some gender-specific PA-related factors, such as body image, among severely obese women unexplored. In addition, studying overweight and obese individuals may not adequately reveal factors uniquely related to excess weight associated with severe obesity and effects, such as drastic weight loss, conferred by bariatric surgery.

Thus, the goal of this study was to explore perceived barriers and facilitators to adopting and maintaining regular PA among women who had recently undergone bariatric surgery. A more comprehensive understanding barriers and facilitators to PA in this unique population will a) assist health care professionals in counselling patients and prescribing effective PA strategies that will facilitate long-term weight loss maintenance, and b) provide evidence-based details to design a tailored exercise program that can be sustainable in clinical practice.

\section{Methods}

\section{Participants}

A purposeful sample of twelve women (mean age $=47 \pm 9$ years) was recruited from a bariatric clinic in a large Canadian city. Participant recruitment was performed by placing advertising posters throughout the clinic and by word of mouth. Originally, forty-five participants contacted the lead author for more information. Twenty-five 
women met the criteria for inclusion and 12 women completed the study. Criteria for inclusion included: (a) within 24 months of having undergone any type of bariatric surgery (e.g., Roux-en-Y gastric bypass, sleeve gastrectomy, laparoscopic banding, or duodenal switch); (b) no physical disability (i.e., requiring the use of an assistive mobility device) that would limit participation in PA; and (c) English speaking. The time frame of 24 months post-surgery was chosen to capture the short-term transition period from pre to post-surgery when patients are losing a significant proportion of baseline body weight, or have plateaued following their peak weight loss, and are no longer prohibited to exercise due to the surgical procedure itself (Hwang et al. 2009). Pseudonyms were adopted to ensure participant anonymity for the purposes of the study. All other identifying characteristics, and names of individuals not directly involved in the study (e.g., names of family members, physicians, personal trainers, etc.), have also been removed. The Institutional Faculty of Medicine Review Board approved the study and written informed consent was obtained from all participants before gathering any data.

\section{Data Gathering}

Participants were first asked to answer a questionnaire providing basic sociodemographic information, followed by the International Physical Activity Questionnaire (IPAQ)- Short (Craig et al. 2003) and the Impact of Weight on Quality of Life (IWQOL)- Lite questionnaire (Kolotkin et al. 1997). The IPAQ-Short is a self-report, validated surveillance measure of walking, moderate, and vigorous PA undertaken in leisure time, domestic/gardening activities, work-related, and transport- 
related activity domains. A categorical score of low, moderate, or high, is calculated using both the total volume and number of session of activity per week whereby a 'low' category score indicates insufficient PA to meet recommended guidelines. The IPAQ-Short is frequently utilized in studies with bariatric patients (Craig et al. 2003, Bond et al. 2011). The IWQOL-Lite is a validated 31-item obesity-specific quality of life measure with adequate psychometric properties and it is a popular tool in bariatric surgery studies. (Kolotkin et al. 1997, De Zwaan et al. 2002). IWQOL-Lite provides scores ranging from 0 (worst) to 100 (best) over five domains: physical function, selfesteem, sexual life, public-distress, and work (Kolotkin et al. 2003, Kolotkin et al. 2008). Finally, height was measured using a wall-mounted stadiometer while weight was measured with light clothing and no shoes, using a digital scale (Seca, Hamburg, Germany).

Women were interviewed once in person by the senior author (AD) using a semi-structured interview protocol. Semi-structured individual interviews are used extensively in health care research and offer flexibility and opportunities for elaboration about specific experiences (Gill et al. 2008). Participants were asked to describe their experiences with exercise and PA (both prior to surgery and after); feelings and thoughts surrounding these experiences; reasons for discontinuation of regular PA or exercise; as well as reasons for engaging in and maintaining PA or exercise. Both periods of physical activity and inactivity (pre and post bariatric surgery) were explored during interviews. Interviews lasted on average 58 minutes (range: 42 - 106 minutes) and were conducted until data saturation was established, 
with no new information emerging from the interview sessions across cases (Denzin and Lincoln 2005).

\section{Data Analysis}

All interviews were audio recorded, transcribed, and organized using QSR NVivo-9 software for qualitative research analysis (QSR International 2011). Prior to analysis, transcripts were re-read for accuracy and familiarization with the interview data. An inductive thematic analysis approach was used whereby the themes developed are tightly linked to the data themselves (Braun and Clarke 2006). A thematic analysis is an appropriate analytical method for studies that aim to describe participant realities, experiences and meanings in rich detail through systematic organization of interview data (Boyatzis 1998). All sentences, or phrases, of interview data were initially coded systematically into meaningful units (i.e., codes), which refer to the most basic element of data. Names for the basic units of analysis were developed from quotes that reflected participants' experiences. Next, similar codes were combined into broader level categories (i.e., sub-themes), which were then organized into themes to represent the broadest level of data (Braun and Clarke 2006).

\section{Trustworthiness}

A number of strategies were implemented to ensure trustworthiness of data including member checking of interview transcripts, data triangulation, and peer debriefing (Yardley 2000). Member checking is frequently used in qualitative research to reinforce methodological soundness (Lincoln and Guba 1985). Participants were asked to review a copy of their transcript to ensure that their experiences were 
accurately represented. In case of discrepancy, participants provided feedback and changes were made accordingly. All participants completed the member checking process: three participants made minor changes, one participant provided additional in-depth feedback, and all other participants agreed that the transcripts captured their interview accurately.

Data triangulation serves to minimize possible chance associations made during data analysis and strengthens study trustworthiness, by drawing on various sources of information to confirm the data presented during interviews (Thurmond 2001). Triangulation was performed by comparing interview data with the results of the IPAQ Short and IWQOL- Lite questionnaires as well as the researcher's (AD) interview notes that noted participant body language, mood, and further elaboration provided by participants post-interview.

Finally, a peer reviewer (MC) independently coded three transcripts using a list of the categories and themes, as well as their respective definitions, which were developed during analysis by AD. In case of disagreement with coding, the lead researcher and peer reviewer engaged in discussion until consensus was reached (Yardley 2008). The peer debriefing process resulted in 90\% inter-coder agreement.

\section{Interview Findings}

At the time of the interview, participants were on average 15 months post-bariatric surgery (range: 9-19 months). Table 1 provides a summary of selected participant characteristics. Eleven women reported moderate to high levels of PA over the seven- 
day period. One participant, Connie, underwent a surgical procedure prior to the interview and had been advised to limit PA for six weeks, and thus reported low levels of PA over the seven-day period. All women discussed lengthy periods of physical inactivity, some lasting decades and especially in the years leading up to their surgery. Table 2 provides participants' IWQOL-Lite domain scores. However, only three of the domain scores (e.g., physical function, self-esteem, and public distress) were consisted with participant interview data. Work and sexual life domain scores did not appear to reflect interview data.

\section{Thematic Analysis}

Three major interrelated themes emerged during the course of analysis: the physical body, appraisal of the physical and social self, and the exercise environment. Each theme encompasses barriers, facilitators, and motivators to PA. Of note, some barriers and facilitators were reported exclusively in reference to the post-operative period (see Table 3).

\section{The physical body}

The physical body theme represents statements pertaining to barriers or facilitators physiologically experienced by women when engaging in PA.

\section{Barriers}

All women experienced at least one weight-related mobility issue such as global pain, joint pain, ligament injury, or a lack of cardiorespiratory fitness. 
Jane (on PA pre-surgery): It was hard, it was still hard cause it was so much weight to have to walk on the treadmill, you know. I had problems with my feet, and that started - what's it calledplantar fasciitis. That started up again, so I had to stop exercising for a while, which wasn't very good, for a few months because it was so painful to walk on my foot... I mean that was a direct result of my weight. And I had serious problems with my knees. I could barely walk and I coach and it was very painful to walk. So, I'd have my daughter show some of the drills that I needed to do because I couldn't do it because my knees were hurting so bad.

Quite often, impaired mobility perpetuated physical inactivity and contributed to subsequent weight gain that further exacerbated mobility-related barriers.

Cathy (on PA pre-surgery): Well, when you're heavier you're less active...the more weight I gained, the less active...I didn't feel like doing it, I didn't want to do it... and I was unable to do it. I mean it just, you know, the weight... it just escalated.

Additionally, women reported decreased energy and stamina levels, as a consequence of personal challenges (e.g., co-morbidities such as sleep apnea and hypothyroidism) and occupational demands (e.g., shift work). 
In some cases, bariatric surgery resulted in changes to bodily systems that impacted fluid intake and eating in relation to exercise. Some women also described developing excess loose skin, in months following surgical weight loss, which impacted their comfort during exercise. These changes required additional planning of daily PA by focusing on timing of meals, adequate hydration, and use of support garments during exercise.

Joanna: Something that goes with the surgery is that you cannot eat and drink at the same time. And when you eat, you cannot drink 45 minutes afterwards. So, when I decide to do an exercise, I have to plan. I cannot shovel the snow after having my meal. I have to wait because when I do an exercise I get thirsty very, very easily.

Claire: So, now it's not as bad, the skin is a bit tighter but when I run or do anything that requires uh, impact, I wear either a umm support undergarments or when I run, well I've bought running tights, support running tights... very, very, very supportive bras because your boobs just go when you lose the weight. But they don't go, they don't disappear, you're just left with a lot of loose skin that can be very painful if you don't support it well.

\section{Facilitators/Motivators}

All participants commented that the substantial weight loss, induced by surgery, had a positive impact on their ability to be physically active. Bariatric surgery resolved many of the mobility issues and co-morbidities (e.g., sleep apnea) that limited PA prior to surgery. 
Connie (on PA post-surgery): I can bend, I can fold, cross my legs, I can tie my shoes. I can jog on the treadmill. I used to walk for 5 min and my lower back would kill me on the treadmill. Now, I can jog like for 5 minutes non-stop and with the incline so for me that's like wow.

With increased physical function and substantial weight loss following surgery, participants reported that health and long-term weight maintenance concerns provided new motivation to be physically active.

Barbara (on PA post-surgery): I have my family. I'm doing this mostly because I want to live longer. I want to be there for my kids and because I see now that exercise saves you in every way either health-wise, relationship-wise, how the world sees you.

\section{Appraisal of the physical and social self}

The theme appraisal of the physical and social self addresses interrelated social, cognitive, and behavioural factors pertaining to PA engagement.

\section{Barriers}

Body dissatisfaction was a prominent psychosocial barrier to PA. Almost all of the women reported experiencing feelings of shame, embarrassment, and discomfort about their bodies, especially when appearing in public. Body dissatisfaction was mentioned as a barrier to PA in reference to pre and post surgical time frames. Participants also reported comparing their body shape and progress to that of others 
when exercising, which further reinforced feelings of self-consciousness and inability to be physically active.

Danika: You're going [to the gym] and you're seeing all these people who are like trim or fit and they're active and they're doing what they do. They're doing the things and making it look so easy and you feel like so klutzy... You... kinda, you feel out of place.

Jane: I felt embarrassed about going [to the gym]. It was difficult because I've been there for so long, I was there for 5-6 months, and there really wasn't much of a difference physically. I felt like ok they're probably watching me and thinking she didn't lose any weight.

Lack of self-efficacy to regularly engage in PA was another barrier frequently discussed by participants, irrespective of the surgical period. Women reported feeling self conscious about having inadequate skills or ability to engage in various forms of PA.

Joanna: I was always the worst player, the worst skier, the worst--yeah maybe that's why I never like to exercise. I don't feel that it's something that I'm good at. Many women reported difficulty persisting with exercise related tasks and goals and subsequently avoided situations that highlighted their physical limitations related to PA.

Judy: You're not going to put yourself in a situation where they're going to ask you to start touching your toes because your body is just, the weight is just 
stopping you. The structure of it is just stopping you and to be always in a situation where you're going to be reminded that you can't, it's just something else you can't do, you're going to not do it.

Lack of confidence with PA tended to persist for some participants despite experiencing improvement in physical function following substantial post-surgical weight loss. One woman described difficulty with mentally adjusting to her smaller body size and continued to perceive herself as too obese to exercise.

Jane: I think I'm still thinking in the mindset that I'm still super, morbidly obese and I can't do it, which I'm slowly starting to get out of that mind frame...But I think that's basically what's stopping me. Like I'm still thinking that I can't do it.

Furthermore, reduced exercise self-efficacy appeared to contribute to, and in part be sustained by, a lack of motivation and negative attitudes towards PA. Specifically, some women reported a dislike for perspiring during strenuous PA and many described exercise as 'taxing', a 'chore' and a 'waste of time'. For some women, a lack of social support and having few relationships that included being physically active together contributed to the absence of positive PA-related experiences and reduced opportunities to be physically active.

June: My friends here... are not very active. So... when I've tried to get them to maybe come with me [to exercise], they're not interested. So maybe if I'm in that type of environment, maybe I'll be different, you know. Cause I think it's...how you're brought up, too... who you hang around with, so if your 
friends are not active, you're not going to be active either.

Compromised psychological health was also a salient hurdle to PA, both pre and post surgery. Several women cited a history of depression and reported ongoing issues with low mood and emotional strain. Additionally, some reported a history of stressful life events (e.g., childhood sexual abuse and divorce) that impacted their interest in being physically active.

Cathy: It's a mind thing to get back to exercising and feeling good about you as a person...that you're worth something instead of always being in a hole thinking you're nothing... that's where I think a lot of my problems were.

Connie: I was ...sexually molested at 8 and then it's as if from that age on, everything just seemed to change. I didn't want to go out. I didn't want to exercise [sigh] and food became like my best friend. And so I became closer to food than, than to exercise. And then food comforted me and it also protected me so that I wasn't attractive to my uncle or other male predators at that time.

Several participants reported that it was often a struggle to make time for daily PA due to competing responsibilities that included occupational and educational demands as well as family responsibilities.

Lucy: I stuck with it for as long as I could. I was there [at the gym] for about 4 or 5 months. Then I had to prepare for lectures and symposia, etc. I was studying a lot and I just couldn't. When it came to getting active- even taking an extra walk or something — made it more difficult. 


\section{Facilitators/Motivators}

For most women body image, positive or negative, appeared to increase motivation for being physically active. Women reported the inability to fit comfortably into their clothing as motivation to increase their levels of PA. Similarly, post surgical weight loss improved body image and motivated many to maintain appearance by being physically active.

Barbara: Just seeing every single week that change in my body would make would motivate me to want to do the gym. You know, because seeing yourself when you're that heavy and seeing yourself become this different person, you want to go to the gym. You want to stay in shape.

When women did report being physically active on a regular basis, they discussed social support, maintenance of physically active relationships, and enjoyment of meaningful activities as primary motivators during these times. Barbara, who was physically inactive prior to surgery, overcame her initial reluctance to go to an exercise facility post-surgery by bringing friends for support.

Barbara: It was different; it was embarrassing ... I wanted somebody with me as a friend at the beginning. I would bring a few friends with me... Just to have company because it was something new. But after like a month that I got the hang of it, I would go alone.

In fact, a number of participants reported using a variety of behavioural strategies such as recruiting PA partners, engaging in positive self-talk, goal setting and journaling about their exercise experiences in order to maintain regular PA. 


\section{The exercise environment}

The theme of exercise environment describes factors within the individual's social and physical environments that impacted their ability to be physically active.

\section{Barriers}

Participants discussed challenges with access to accommodating facilities and equipment where they could safely and comfortably exercise, especially when they were severely obese. Additionally, many women described costs, inconvenient facility locations, and difficulty finding appropriate exercise clothing for a larger body as barriers to being physically active. Reduced access to exercise facilities due to membership costs was a significant concern for participants with lower incomes, though some were able to circumvent this barrier. For example, one woman was able to negotiate use of the neighbourhood community pool at a reduced rate. However, because her primary strategy for PA involved participating in a swimming group, she was concerned about access to this facility in the future.

Lucy: I swim at our community pool. Residents get a special price for being a member of the community, as well as giving to the pool... I have to make sure, being on a fixed income, that I'm able to fit in a class at least.

Beyond access to appropriate facilities, women cited having inadequate access to knowledge about safe exercise techniques that were accommodating to individuals living with excess weight.

Connie: You can't do too much cause your joints are sore, so I guess I wasn't impressed with the trainers at the gym. I wasn't really impressed with their 
knowledge also about having extra weight and they were more like muscle... muscle gyms that I went to I guess. And it wasn't a very personalized, like you had an hour with them and...even during the session I found that they were not really there with you they were just looking around.

Of interest, when asked about PA-related discussions with healthcare professionals, all participants recalled receiving general advice to lose weight and exercise regularly. However, few women received specific strategies, and most felt they only received cursory advice to exercise.

Connie: They [physicians] didn't really spend much time talking about physical activity they just basically said, "You have to lose weight, exercise, walking”. It was not a big discussion... you know ... 'Try walking half an hour then bring it up to 45 minutes' it was just like a general, overall 'You know you have to lose weight and exercise plays a big role' and that was basically it.

Danika: I knew I needed to lose weight and then I'm always thinking, they [physicians] make it sound like it's so easy. It's not easy, you know? They're all slim and trim, they don't have to worry about this weight and how to get rid of it so they think it's easy. It's hard, it's not easy.

Several women discussed challenges associated with maintaining regular PA during winter in a northern climate, as it not only limited the types of activities one could engage in, but also decreased motivation for PA. 
Jessica: I found that when you get home in the winter and then you have to go back out for a class at 7:30, you miss a bunch of classes ... you get home and you're tired, now you're home and you've put your comfy clothes and you've put your feet up. And now you're going to go back out in the cold in January or February for an hour exercise class. That was never going to happen.

In order to circumvent weather-dependent barriers, some participants structured exercise sessions at optimal times to reduce the impact of decreased motivation. For example, committing to exercise at the gym at the end of the workday on their way home appeared to be a particularly helpful strategy for several participants.

\section{Facilitators/Motivators}

Access to facilities with a pool often facilitated regular PA for many women. Activities such as water-based exercise and swimming helped reduce joint pain and also minimized the visibility of excess skin movement, and thus were frequently reported forms of PA.

Amy: I decided to go...try Curves and I liked the atmosphere and I liked the hydraulic gym equipment. I figured, you know what, I'm going to give this a shot... [The staff] are very nice there. And they're always, talking to me, encouraging me and I had wonderful trainers. They push me and they're always there to support me. If I have a problem, I can talk to them about it and they try to give me their perspective. 
Frequently, exercise knowledge provided by active friends, personal trainers, or the bariatric team motivated participants to adopt and maintain regular PA. Women who reported long periods of physical inactivity and inexperience with exercise found specific start-up information from exercise professionals particularly helpful as they increased their PA levels following surgery.

Danika: I had a trainer for a couple of times and then I learnt a lot from that so then I did that on my own and I liked it. I've never had one before and...they were able to tell you exactly what you need to do for the arms, or you need to do for the stomach or the legs.

One participant also recalled being given an exercise prescription from her doctor along with a discount coupon at a local gym that significantly reduced gym memberships costs and encouraged more regular PA.

Lucy: It was incentive. And that incentive pushed me to stick with it. I kept saying to myself: How many times do you get a prescription to exercise at a gym?

Over all, interview data revealed three main, interrelated themes: the physical body, appraisal of the physical and social self, and the exercise environment. Table 3 provides a summary of the main themes and the respective sub-themes (categories), as well as reported prevalence of sub-themes. 


\section{Discussion}

To our knowledge, this is the first study to explore perceptions of barriers, facilitators, and motivators to adopting and maintaining a physically active lifestyle among severely obese women who had undergone bariatric surgery. Our exploratory study included 12 women who underwent weight loss surgery within the last two years in a large urban centre in Canada. Our results suggest complex, interrelated relationships among the three themes for the adoption and maintenance of regular PA, and are discussed within the following section with suggested approaches to exercise programming and counselling strategies when working with women who undergo bariatric treatment.

One of the most salient physical barriers to PA among this group of severely obese women was limited mobility due to body size, global and local joint pain, as well as low levels of physical fitness. Consequently, reduced physical function appeared to impact self-efficacy and motivation for exercise, and fostered avoidance attitudes and behaviours for some participants. Declining levels of activity may be part of a cascade of events that lead to a spiral of negative health consequences including reduced mobility, muscle strength, flexibility and endurance; along with increasing pain and discomfort with subsequent bouts of PA. Collectively, these events may serve to exacerbate PA-related fears. Our findings are similar to studies investigating pain and disability in other patient populations. Patients with chronic back pain and musculoskeletal disorders also report PA-related pain, which 
contributes to fear-avoidance behaviour, thereby negatively impacting self-efficacy and reducing participation in PA (Geisser et al. 2000, Damsgard et al. 2010).

Bandura's Self-Efficacy Theory may help explain the lack of confidence in adopting and maintaining a physically active lifestyle observed among participants. Initiation and maintenance of a given behaviour is dependant on three contextually flexible factors: 1) self-efficacy (i.e., belief in one's ability to carry out an action); 2) outcome expectancies that follow a given behaviour; and 3) the value judgment placed on the expected outcome (Bandura and Adams 1977). Self-efficacy may be affected by past performances, vicarious experiences, social persuasion and physiological/affective states (Bandura 1999). Specifically, physical consequences associated with excess weight (e.g., increased joint and body pain) coupled with negative physical and psychological experiences during activity may contribute to perceptions of limitations in exercise capability, which in turn, may undermine adoption and maintenance of PA.

Furthermore, PA-avoidance behaviours may develop early in life and reinforce life-long physical inactivity. Childhood obesity may alter posture and centre of gravity, leading to musculoskeletal pain, and ultimately impair movement (Wearing et al. 2006a, Wearing et al. 2006b,). Thus, development of exercise programming for severely obese women, who were overweight or obese as children like many of our participants, necessitates an appreciation of lifelong physical limitations and altered body mechanics in response to living with excess weight. 
Similar to others, our findings also revealed a prevailing belief of diminished exercise capacity and negative somatic perceptions characterized by a heightened response during exercise. This heightened physiological response may prompt comparisons to others when exercising in group settings, leading to increased frustration and self consciousness about fluidity of movement as well as embarrassment at increased perspiring and breathlessness. Moreover, anticipation of increased pain post-exercise in combination with the aforementioned negative states may ultimately dampen motivation to persist with regular PA or exercise (Wingo et al. 2010, Ekkekakis et al. 2011). Therefore, traditional aerobic and resistance exercise regimens featuring percussion, which can increase joint pain, flexibility (e.g, toe touching), rapid changes in posture or position (e.g., toe-touching, alternating floorbased and standing exercises), strenuous cardiovascular activity, or balance (e.g., tree pose) are not optimal for obese individuals. Additionally, these findings speak to the importance of gradually increasing levels of PA among severely obese individuals so as to minimize muscle soreness and pain. Given that obese individuals may use as much as 60 percent of their maximal oxygen capacity during walking, instruction to also gradually increase daily walking, or activities of daily living to increase overall stamina can help reduce fatigue (Poirier and Després 2001).

Thus, PA-promoting initiatives should also teach severely obese individuals to anticipate some physiological symptoms post exercise (e.g., transient mild stiffness and muscle aches, increased perspiration as fitness improve) and reinterpret these sensations more positively as indications of improvement so as to cultivate exercise 
self-efficacy (Mcauley and Courneya 1993). For example, motivational interviewing has been used to help obese African American women with mobility disabilities identify and circumvent individual barriers to PA (Rimmer et al. 2010). Exercise physiologists with severe obesity- specific training helped participants navigate these challenges through education, reassurance, and individually tailored suggestions that emphasized activities of daily living featuring household chores, leisure walking as well as structured exercise. Post-intervention, the average exercise time among participants increased from $<6$ minutes/day to 27 minutes/day while total PA time increased from 26 minutes/day to 89 minutes/day (Rimmer et al. 2010) These findings suggest that an individually tailored approach, which acknowledges physical limitations and health concerns among severely obese individuals, can be highly effective at increasing the likelihood of PA adoption.

In order to effectively help women who are severely obese or have a history of severe obesity, exercise and healthcare professionals must understand the broad spectrum of factors that contribute to PA limitations, negative exercise attitudes, and a lack of exercise self-efficacy. Exercise specialists should acquire additional expertise in the impact of excess weight on biomechanics, individual capabilities, and comfortable physical activities for this population group. It is also important to understand the individual's pain-related concerns, perceived physical limitations and PA-related anxieties.

Our interview and questionnaire data both offer evidence that weight loss associated with bariatric surgery reduced, or even resolved, the majority of mobility 
impairments and physical body barriers that impeded PA among participants. Reductions in pain-related disability and the resolution of mobility- limiting comorbidities (e.g., lower back and knee pain) are consistently reported improvements associated with bariatric surgery (Bocchieri et al. 2005, Hooper et al. 2006)). Only one participant reported an IWQOL-Lite physical function score below the $50^{\text {th }}$ percentile. This participant also had the highest BMI $\left(43.8 \mathrm{~kg} / \mathrm{m}^{2}\right)$ at the time of the interview, second highest pre-surgical BMI $\left(60.1 \mathrm{~kg} / \mathrm{m}^{2}\right)$, and had most recently (i.e., 9 months) undergone bariatric surgery compared to all other participants.

However, even though physical function and mobility often improve post surgery, our findings also emphasize that new potential barriers may emerge following surgical intervention. Specifically, some women found that new strategies were required to optimize adequate energy and water intake relative to exercise sessions. Because the goal of bariatric surgery is to significantly restrict food intake to $600-1000 \mathrm{kcal}$ per day (O'Brien 2010), participants may need to be taught how to plan meals and snacks in relation to bouts of PA, and modulate intensity and duration to ensure adequate hydration. Furthermore, the excess skin movement that results in response to substantial weight loss can also introduce physical discomfort and embarrassment. To accommodate painful excess skin movement, and remaining joint and body pain, the use of support garments and water-based activities such as swimming can be considered. Indeed, our participants indicated a preference for water-based activities because they minimized physical and psychological consequences of excess skin related to rapid weight loss. However, it is important 
that the social and physical environments of such mobility-accommodating programs are also sensitive to body image concerns among severely obese women.

Participants repeatedly discussed negative perceptions of body image and fear of negative evaluation when exercising around others as barriers to PA, irrespective of pre or post-surgical time frames. These findings are consistent with literature surrounding the pervasiveness of dissatisfaction with body image among women in Western culture (Cash and Henry 1995) and specifically, among obese women given that body image dissatisfaction tends to increase with weight (Sarwer et al. 1998, Schwartz and Brownell 2004). Our quantitative and qualitative data suggest that these concerns are prevalent for many women before and after surgery. The IWQOL-Lite self-esteem scores in Table 2 indicate scores below the $55^{\text {th }}$ percentile for seven participants indicating that negative image perceptions may perpetuate irrespective of excess weight loss.

Napolitano et al. (2011) observed that body image based PA barriers impacted PA levels among moderately obese women. Overweight and moderately obese women not only report a greater number of barriers to PA, but they are also more likely to report barriers, such as 'feeling self conscious when I do activities' and 'I am too overweight', significantly more frequently than normal weight women. The nature and frequency of barriers subsequently negatively impacts levels of PA. For example, among moderately obese women, those who reported fewer barriers achieved 70 minutes /week more of exercise than those in the high barrier group (Napolitano et al. 2011). Thus, effective exercise programming for this population 
should also focus on cognitive behaviour therapy interventions to curb body image disturbances among severely obese women through modification of intrusive thoughts, negative weight-related stereotypes and overvalued judgements about physical appearance (Rosen et al. 1995, Ramirez and Rosen 2001).

Among motivators for PA, our participants reported mostly extrinsic motivators such as post-operative weight and health maintenance as motives for engaging in PA. These results suggest that our participants were likely still in the acquisition stage of exercise behaviour versus the maintenance stage, according to the stages of change construct developed by Prochaska et al. (1992). As individuals move towards the maintenance stage of behaviour change, they may tend to shift exercise motivation to more intrinsic motivators such as fun and personal improvement (Ingledew et al. 1998). Our finding is not entirely surprising given that health and weight maintenance motivators were discussed exclusively in reference to the postsurgical period. Most of the participants were still in process of losing weight and may have experienced perceived improvement in body image at the time of their interviews. Thus, exercise specialists and healthcare professionals working with severely obese women undergoing weight loss treatment should help individuals identify and leverage extrinsic motivators for PA, such as joining an exercise group, or combining social activities with opportunities to be physically active to help facilitate adoption of regular PA. And to increase likelihood of long-term PA adherence, PA programming for this group should help to increase autonomous motivation for exercise by creating enjoyable exercise experiences given that intrinsic 
motivators for exercise are strongly associated with PA maintenance (Markland and Ingledew 2007).

Finally, our participants noted the challenges of remaining active in a northern climate as others have also observed (Andajani-Sutjahjo et al. 2004, Gordon-Larsen et al. 2004). Climate-related barriers require consideration of additional strategies to facilitate continued activity during winter by placing emphasis on walking, use of hiking poles for increased stability on slippery surfaces, indoor walking at malls, and access to conveniently located exercise facilities. Furthermore, identifying weatherrelated barriers early on in exercise programming will allow for development of alternative individual strategies for the months of the year when outdoor weather is a barrier to PA for individuals.

As Giles-Corti and Donovan (2002) have previously suggested, the relative influence of the physical environment on habitual PA may be secondary to individual and social determinants of PA. Similarly, we noted that environmental barriers were discussed less frequently among participants in comparison to physical and psychosocial barriers such as mobility limitations and body dissatisfaction. Therefore, it is important to help participants identify facilities that are not only affordable and conveniently located, but they must also help circumvent many of the aforementioned physical and psychosocial barriers for obese women. However, facility accessibility (i.e., presence of elevators or ramps) is likely to be necessary but insufficient for maintenance of regular PA when individuals have disability issues (Rolfe et al. 2012). For example, inadequate disability-specific training among staff can lead to 
feelings of alienation and reduced participation in group-based exercises among participants (Rolfe et al. 2012). Hence, the exercise professional's role in this context should not be limited to informational support about exercise techniques. Specialists should also become an integral part of the patient's social support network by providing encouragement, actively listening to individual PA history and PA-related fears, and tailoring programs accordingly.

Studies suggest that approximately 17 percent of women seeking bariatric treatment report a history of childhood sexual abuse (Gustafson et al. 2006). History of sexual abuse is also associated with development of obesity and binge eating disorders (Gustafson and Sarwer 2004, Noll et al. 2007). Accounts of such traumatic life events underscore the need for a compassionate approach among healthcare professionals when engaging in PA-related dialogue with severely obese patients. This finding also speaks to the importance of identifying mental health resources in the community that can provide additional assessment when needed to address longstanding issues that may impede the successful adoption and maintenance of regular $\mathrm{PA}$.

Collectively, our study findings highlight three key themes that encompass the physical body, appraisal of the physical and social self, and the exercise environment among female bariatric patients; a unique population that is understudied to date. These results should help healthcare professionals, working with severely obese women tailor PA counselling strategies, both prior to and after bariatric surgery. Additionally, our findings offer insight into interrelationships between factors such as 
functional limitations related to weight, body image disturbances, and a lack of selfefficacy in relation to PA. Tailored counselling strategies and programs aimed at these multidimensional needs are highly relevant to adoption and maintenance of healthful PA levels in women who have undergone weight loss surgery.

We chose to focus on women given that they have a higher prevalence of severe obesity coupled with lower rates of PA, and are more likely to undergo bariatric surgery than their male counterparts. Our group reflects the lived experience of a range of severely obese women across a diverse range of ages spanning 35 to 61 years. Future studies should also explore this phenomenon across settings, in racially and economically diverse groups, among men, as well as individuals who have surpassed the two-year peak weight loss-plateau period post-bariatric surgery. Beyond two years, there is likely to be increased variability in weight change, body image, and psychosocial adjustment that may further impact motivation, interest and confidence to be physically active.

In summary, women who undergo bariatric surgery treatment report multiple interrelated barriers and facilitators with respect to adopting and maintaining a physically active lifestyle. A more comprehensive understanding of barriers and facilitators to PA encountered by this population can help healthcare providers and exercise professionals tailor their individualized counselling and exercise programming approach. An individualized approach that identifies personal as well environmental barriers, and leverages facilitators, can help facilitate long-term weight loss maintenance through adoption and maintenance of regular PA. Sustainability of 
an active lifestyle remains a critical, but unmet, goal of the post-bariatric treatment paradigm, as regular PA remains to be one of the strongest predictors of long-term weight loss maintenace. 


\section{References}

Aills, L., Blankenship, J., Buffington, C., Furtado, M. \& Parrott, J., 2008. ASMBS Allied Health Nutritional Guidelines for the Surgical Weight Loss Patient. Surgery for obesity and related diseases : official journal of the American Society for Bariatric Surgery, 4, S73-S108.

Andajani-Sutjahjo, S., Ball, K., Warren, N., Inglis, V., \& Crawford, D. (2004). Perceived personal, social and environmental barriers to weight maintenance among young women: A community survey. Int J Behav Nutr Phys Act, 1(1), 15. doi: $10.1186 / 1479-5868-1-15$

Bandura, A. (1999). Self-efficacy: Toward a unifying theory of behavioral change.

Bandura, A., \& Adams, N. E. (1977). Analysis of self-efficacy theory of behavioral change. Cognitive therapy and research, 1(4), 287-310.

Bocchieri, L. E., Meana, M., \& Fisher, B. L. (2002). Perceived psychosocial outcomes of gastric bypass surgery: a qualitative study. Obes Surg, 12(6), 781-788. doi: 10.1381/096089202320995556

Bond, D. S., Jakicic, J. M., Unick, J. L., Vithiananthan, S., Pohl, D., Roye, G. D., . . . Wing, R. R. (2010). Pre- to postoperative physical activity changes in bariatric surgery patients: self report vs. objective measures. Obesity (Silver Spring), 18(12), 2395-2397. doi: 10.1038/oby.2010.88

Bond, D. S., Unick, J. L., Jakicic, J. M., Vithiananthan, S., Pohl, D., Roye, G. D., . . . Wing, R. R. (2011). Objective assessment of time spent being sedentary in bariatric surgery candidates. Obes Surg, 21(6), 811-814. doi: 10.1007/s11695010-0151-x

Boyatzis, R.E., 1998. Transforming Qualitative Information: Thematic Analysis and Code Development. Sage.

Braun, V., \& Clarke, V. (2006). Using thematic analysis in psychology. Qualitative research in psychology, 3(2), 77-101.

Bryan, S., \& Walsh, P. (2004). Physical Activity and Obesity in Canadian Women. BMC Womens Health, 4 Suppl 1, S6. doi: 10.1186/1472-6874-4-s1-s6

Buchwald, H., \& Williams, S. E. (2004). Bariatric surgery worldwide 2003. Obesity surgery, 14(9), 1157-1164.

Cash, T.F. \& Henry, P.E., 1995. Women's body images: The results of a national survey in the USA. Sex roles, 33, 19-28. 
Christou, N. V., Look, D., \& Maclean, L. D. (2006). Weight gain after short- and long-limb gastric bypass in patients followed for longer than 10 years. Ann Surg, 244(5), 734-740. doi: 10.1097/01.sla.0000217592.04061.d5

Colley, R. C., Garriguet, D., Janssen, I., Craig, C. L., Clarke, J., \& Tremblay, M. S. (2011). Physical activity of Canadian adults: accelerometer results from the 2007 to 2009 Canadian Health Measures Survey. Health Rep, 22(1), 7-14.

Craig, C. L., Marshall, A. L., Sjostrom, M., Bauman, A. E., Booth, M. L., Ainsworth, B. E., .. . Oja, P. (2003). International physical activity questionnaire: 12country reliability and validity. Med Sci Sports Exerc, 35(8), 1381-1395. doi: 10.1249/01.mss.0000078924.61453.fb

Damsgard, E., Thrane, G., Anke, A., Fors, T., \& Roe, C. (2010). Activity-related pain in patients with chronic musculoskeletal disorders. Disabil Rehabil, 32(17), 1428-1437. doi: 10.3109/09638280903567877

De Zwaan, M., Mitchell, J. E., Howell, L. M., Monson, N., Swan-Kremeier, L., Roerig, J. L., . . Crosby, R. D. (2002). Two measures of health-related quality of life in morbid obesity. Obes Res, 10(11), 1143-1151. doi: 10.1038/oby.2002.155

Denzin, N. K., \& Lincoln, Y. S. (2005). The Sage Handbook of Qualitative Research 3rd edition. Thousand Oaks: Sage Publications.

Ekkekakis, P., \& Lind, E. (2006). Exercise does not feel the same when you are overweight: the impact of self-selected and imposed intensity on affect and exertion. Int J Obes (Lond), 30(4), 652-660. doi: 10.1038/sj.ijo.0803052

Ekkekakis, P., Parfitt, G. \& Petruzzello, S.J., 2011. The pleasure and displeasure people feel when they exercise at different intensities. Sports Medicine, 41, 641-671.

Gallagher, K. I., Jakicic, J. M., Napolitano, M. A., \& Marcus, B. H. (2006).

Psychosocial factors related to physical activity and weight loss in overweight women. Med Sci Sports Exerc, 38(5), 971-980. doi: 10.1249/01.mss.0000218137.25970.c6

Geisser, M. E., Haig, A. J., \& Theisen, M. E. (2000). Activity Avoidance and Function in Persons with Chronic Back Pain. Journal of Occupational Rehabilitation, 10(3), 215-227. doi: 10.1023/a:1026666403039

Giles-Corti, B., \& Donovan, R. J. (2002). The relative influence of individual, social and physical environment determinants of physical activity. Soc Sci Med, 54(12), 1793-1812. 
Gill, P., Stewart, K., Treasure, E., \& Chadwick, B. (2008). Methods of data collection in qualitative research: interviews and focus groups. Br Dent J, 204(6), 291295. doi: $10.1038 /$ bdj.2008.192

Goodpaster, B. H., Delany, J. P., Otto, A. D., Kuller, L., Vockley, J., South-Paul, J. E., ... Jakicic, J. M. (2010). Effects of diet and physical activity interventions on weight loss and cardiometabolic risk factors in severely obese adults: a randomized trial. JAMA, 304(16), 1795-1802. doi: 10.1001/jama.2010.1505

Gordon-Larsen, P., Griffiths, P., Bentley, M. E., Ward, D. S., Kelsey, K., Shields, K., \& Ammerman, A. (2004). Barriers to physical activity: qualitative data on caregiver-daughter perceptions and practices. [Research Support, U.S. Gov't, P.H.S.]. American Journal of Preventive Medicine, 27(3), 218-223.

Gustafson, T.B. \& Sarwer, D.B., 2004. Childhood sexual abuse and obesity. Obesity Reviews, 5, 129-135.

Gustafson, T. B., Gibbons, L. M., Sarwer, D. B., Crerand, C. E., Fabricatore, A. N., Wadden, T. A., . . . Williams, N. N. (2006). History of sexual abuse among bariatric surgery candidates. Surgery for Obesity and Related Diseases, 2(3), 369-374. doi: http://dx.doi.org/10.1016/j.soard.2006.03.002

Hooper, M., Stellato, T., Hallowell, P., Seitz, B. \& Moskowitz, R., 2006. Musculoskeletal findings in obese subjects before and after weight loss following bariatric surgery. International journal of obesity, 31, 114-120.

Huang, J., Yu, H., Marin, E., Brock, S., Carden, D., \& Davis, T. (2004). Physicians' weight loss counseling in two public hospital primary care clinics. Acad Med, 79(2), 156-161.

Huizinga, M., Cooper, L., Bleich, S., Clark, J. \& Beach, M., 2009. Physician Respect for Patients with Obesity. Journal of General Internal Medicine, 24, 12361239.

Ingledew, D. K., Markland, D., \& Medley, A. R. (1998). Exercise motives and stages of change. Journal of health psychology, 3(4), 477-489.

Jakicic, J. M., \& Davis, K. K. (2011). Obesity and physical activity. Psychiatr Clin North Am, 34(4), 829-840. doi: 10.1016/j.psc.2011.08.009

Karmali, S., Stoklossa, C.J., Sharma, A., Stadnyk, J., Christiansen, S., Cottreau, D. \& Birch, D.W., 2010. Bariatric surgery A primer. Canadian Family Physician, $56,873-879$. 
Katzmarzyk, P. T., \& Mason, C. (2006). Prevalence of class I, II and III obesity in Canada. [Research Support, Non-U.S. Gov't]. CMAJ, 174(2), 156-157. doi: 10.1503/cmaj.050806

Kolotkin, R. L., Crosby, R. D., Gress, R. E., Hunt, S. C., Engel, S. G., \& Adams, T. D. (2008). Health and health-related quality of life: differences between men and women who seek gastric bypass surgery. Surg Obes Relat Dis, 4(5), 651658; discussion 658-659. doi: 10.1016/j.soard.2008.04.012

Kolotkin, R. L., Crosby, R. D., \& Williams, G. R. (2003). Assessing weight-related quality of life in obese persons with type 2 diabetes. Diabetes Res Clin Pract, 61(2), 125-132.

Kolotkin, R. L., Head, S., \& Brookhart, A. (1997). Construct validity of the Impact of Weight on Quality of Life Questionnaire. Obes Res, 5(5), 434-441.

Lincoln, Y. S., \& Guba, E. G. (1985). Naturalistic Inquiry. Newbury Park: Sage Publications.

Markland, D., \& Ingledew, D. K. (2007). The relationships between body mass and body image and relative autonomy for exercise among adolescent males and females. Psychology of Sport and Exercise, 8(5), 836-853.

Maxwell, J. A. (1992). Understanding and validity in qualitative research. Harvard educational review, 62(3), 279-301.

Mcauley, E., \& Courneya, K. S. (1993). Adherence to exercise and physical activity as health-promoting behaviors: Attitudinal and self-efficacy influences. Applied and Preventive Psychology, 2(2), 65-77.

McKenna, J., Naylor, P., \& McDowell, N. (1998). Barriers to physical activity promotion by general practitioners and practice nurses. British Journal of Sports Medicine, 32(3), 242-247.

Mechanick, J.I., Kushner, R.F., Sugerman, H.J., Gonzalez-Campoy, J.M., CollazoClavell, M.L., Guven, S., Spitz, A.F., Apovian, C.M., Livingston, E.H. \& Brolin, R., 2008. American Association of Clinical Endocrinologists, The Obesity Society, and American Society for Metabolic \& Bariatric Surgery Medical Guidelines for Clinical Practice for the perioperative nutritional, metabolic, and nonsurgical support of the bariatric surgery patient. Endocrine Practice, 14, 1-83.

Melissas, J., Kontakis, G., Volakakis, E., Tsepetis, T., Alegakis, A., \& Hadjipavlou, A. (2005). The Effect of Surgical Weight Reduction on Functional Status in Morbidly Obese Patients with Low Back Pain. Obesity surgery, 15(3), 378381. doi: 10.1381/0960892053576703 
Napolitano, M. A., Papandonatos, G. D., Borradaile, K. E., Whiteley, J. A., \& Marcus, B. H. (2011). Effects of weight status and barriers on physical activity adoption among previously inactive women. Obesity (Silver Spring), 19(11), 2183-2189. doi: 10.1038/oby.2011.87

Noll, J.G., Zeller, M.H., Trickett, P.K. \& Putnam, F.W., 2007. Obesity risk for female victims of childhood sexual abuse: a prospective study. Pediatrics, 120, e61e67.

O'Brien, P. E. (2010). Bariatric surgery: Mechanisms, indications and outcomes. Journal of Gastroenterology and Hepatology, 25(8), 1358-1365. doi: 10.1111/j.1440-1746.2010.06391.x

Padwal, R. S., Chang, H.-J., Klarenbach, S., Sharma, A. M., \& Majumdar, S. R. (2012). Characteristics of the population eligible for and receiving publicly funded bariatric surgery in Canada. International journal for equity in health, 11(1), 1-8.

Padwal, R. S., Chang, H. J., Klarenbach, S., Sharma, A. M., \& Majumdar, S. R. (2012). Characteristics of the population eligible for and receiving publicly funded bariatric surgery in Canada. Int J Equity Health, 11, 54. doi: 10.1186/1475-9276-11-54

Poirier, P., \& Després, J.-P. (2001). EXERCISE IN WEIGHT MANAGEMENT OF OBESITY. Cardiology Clinics, 19(3), 459-470. doi: http://dx.doi.org/10.1016/S0733-8651(05)70229-0

Prochaska, J.O., Diclemente, C.C. \& Norcross, J.C., 1992. American psychologist, 47, 1102.

Ramirez, E.M. \& Rosen, J.C., 2001. A comparison of weight control and weight control plus body image therapy for obese men and women. Journal of consulting and clinical psychology, 69, 440-446.

Rimmer, J. H., Hsieh, K., Graham, B. C., Gerber, B. S., \& Gray-Stanley, J. A. (2010). Barrier removal in increasing physical activity levels in obese African American women with disabilities. J Womens Health (Larchmt), 19(10), 1869-1876. doi: 10.1089/jwh.2010.1941

Rolfe, D., Yoshida, K., Renwick, R., \& Bailey, C. (2012). Balancing safety and autonomy: structural and social barriers affecting the exercise participation of women with disabilities in community recreation and fitness facilities. Qualitative Research in Sport, Exercise and Health, 4(2), 265-283.

Rosen, J.C., Orosan, P. \& Reiter, J., 1995. Cognitive behavior therapy for negative body image in obese women. Behavior Therapy, 26, 25-42. 
Sarwer, D. B., Dilks, R. J., \& West-Smith, L. (2011). Dietary intake and eating behavior after bariatric surgery: threats to weight loss maintenance and strategies for success. Surgery for Obesity and Related Diseases, 7(5), 644651. doi: 10.1016/j.soard.2011.06.016

Schauer, P. R., Kashyap, S. R., Wolski, K., Brethauer, S. A., Kirwan, J. P., Pothier, C. E., . . Bhatt, D. L. (2012). Bariatric surgery versus intensive medical therapy in obese patients with diabetes. New England Journal of Medicine, 366(17), 1567-1576.

Schwartz, M.B. \& Brownell, K.D., 2004. Obesity and body image. Body image, 1, 43-56.

Shields, M., Carroll, M. D., \& Ogden, C. L. (2011). Adult obesity prevalence in Canada and the United States. NCHS Data Brief(56), 1-8.

Suggs, L. S., McIntyre, C., \& Cowdery, J. E. (2010). OVERWEIGHT AND OBESE SEDENTARY ADULTS' PHYSICAL ACTIVITY BELIEFS AND PREFERENCES. American Journal of Health Studies, 25(2), 69-77.

Thurmond, V. A. (2001). The point of triangulation. Journal of Nursing Scholarship, $33(3), 253-258$.

Tudor-Locke, C., Brashear, M. M., Johnson, W. D., \& Katzmarzyk, P. T. (2010). Accelerometer profiles of physical activity and inactivity in normal weight, overweight, and obese U.S. men and women. Int J Behav Nutr Phys Act, 7, 60. doi: 10.1186/1479-5868-7-60

Wearing, S.C., Hennig, E.M., Byrne, N.M., Steele, J.R. \& Hills, A.P., 2006a. The biomechanics of restricted movement in adult obesity. Obesity Reviews, 7, 1324.

Wearing, S.C., Hennig, E.M., Byrne, N.M., Steele, J.R. \& Hills, A.P., 2006b. The impact of childhood obesity on musculoskeletal form. Obesity Reviews, 7, 209-218.

Wiklund, M., Olsen, M. F., \& Willen, C. (2010). Physical activity as viewed by adults with severe obesity, awaiting gastric bypass surgery. Physiother Res Int. doi: 10.1002/pri.497

Wing, R. R., \& Hill, J. O. (2001). Successful weight loss maintenance. Annu Rev Nutr, 21, 323-341. doi: 10.1146/annurev.nutr.21.1.323

Wingo, B. C., Evans, R. R., Ard, J. D., Grimley, D. M., Roy, J., Snyder, S. W., . . Baskin, M. L. (2011). Fear of physical response to exercise among overweight 
and obese adults. Qualitative Research in Sport, Exercise \& Health, 3(2), 174-192.

Withrow, D. \& Alter, D.A., 2011. The economic burden of obesity worldwide: a systematic review of the direct costs of obesity. Obes Rev, 12, 131-41.

Yardley, L., 2000. Dilemmas in qualitative health research. Psychology \& Health, 15, 215-228.

Yardley, L. (2008). Demonstrating validity in qualitative psychology. Qualitative psychology: A practical guide to research methods, 2, 235-251. 
Tables

Table 1. Selected participant characteristics.

\begin{tabular}{|c|c|c|c|c|c|}
\hline Pseudonym & $\begin{array}{c}\text { Age } \\
\text { (years) }\end{array}$ & $\begin{array}{c}\text { Time since } \mathbf{S x} \\
\quad \text { (months) }\end{array}$ & $\begin{array}{c}\text { Current } \\
\text { BMI }\left(\mathrm{kg} / \mathrm{m}^{2}\right)\end{array}$ & $\begin{array}{c}\text { Pre-Sx BMI } \\
\left(\mathrm{kg} / \mathrm{m}^{2}\right)\end{array}$ & $\begin{array}{c}\text { IPAQ- } \\
\text { Short PA } \\
\text { Level }\end{array}$ \\
\hline Jane & 43 & 9 & 43.8 & 60.1 & Moderate \\
\hline Claire & 35 & 18 & 26.6 & 49.8 & High \\
\hline Lucy & 43 & 12 & 26.3 & 42.5 & High \\
\hline Connie & 38 & 12 & 37.0 & 62.4 & Low $^{\S}$ \\
\hline Joanna & 47 & 19 & 24.5 & 52.9 & Moderate \\
\hline Judy & 46 & 13 & 27.6 & 49.9 & High \\
\hline Amy & 61 & 16 & 32.5 & 52.2 & Moderate \\
\hline Cathy & 57 & 13.5 & 35.1 & 50.7 & High \\
\hline June & 37 & 14 & 30.8 & 47.7 & Moderate \\
\hline Barbara & 38 & 18 & 26.0 & 49.4 & High \\
\hline Danika & 58 & 13 & 28.7 & 51.9 & High \\
\hline Jessica & 55 & 18 & 23.0 & 38.1 & High \\
\hline
\end{tabular}

$\mathrm{Sx}=$ surgery; $\S$ Participant underwent gall bladder surgery two weeks prior to interview and was medically advised to limit PA. 
Table 2. Participant IWQOL-Lite questionnaire scores presented as percentiles.

\begin{tabular}{|c|c|c|c|c|c|}
\hline Pseudonym & $\begin{array}{l}\text { IWQOL- } \\
\text { Lite } \\
\text { Physical } \\
\text { Function* }\end{array}$ & $\begin{array}{l}\text { IWQOL- } \\
\text { Lite } \\
\text { Self- } \\
\text { Esteem* }\end{array}$ & $\begin{array}{l}\text { IWQOL- } \\
\text { Lite } \\
\text { Public } \\
\text { Distress* }\end{array}$ & $\begin{array}{l}\text { IWQOL- } \\
\text { Lite } \\
\text { Sexual } \\
\text { Life* }\end{array}$ & $\begin{array}{c}\text { IWQOL- } \\
\text { Lite } \\
\text { Work* }\end{array}$ \\
\hline Jane & 48 & 18 & 5 & 50 & 44 \\
\hline Claire & 100 & 100 & 100 & 100 & 100 \\
\hline Lucy & 70 & 29 & 85 & 38 & 88 \\
\hline Connie & 98 & 54 & 50 & 50 & 94 \\
\hline Joanna & 91 & 100 & 100 & 100 & 100 \\
\hline Judy & 84 & 50 & 95 & 100 & 100 \\
\hline Amy & 93 & 93 & 100 & 100 & 100 \\
\hline Cathy & 100 & 25 & 95 & 100 & 100 \\
\hline June & 73 & 25 & 70 & 38 & 100 \\
\hline Barbara & 100 & 54 & 100 & 69 & 100 \\
\hline Danika & 95 & 96 & 100 & 100 & 100 \\
\hline Jessica & 100 & 100 & 100 & 81 & 100 \\
\hline
\end{tabular}


Table 3. Prevalence of main themes and sub-themes (categories) among participants.

\begin{tabular}{|c|c|c|}
\hline Main themes & Barriers & Facilitators/Motivators \\
\hline The physical body & $\begin{array}{l}\text { Limited mobility/lack of } \\
\text { fitness }(n=12) \\
\text { Low energy/stamina levels } \\
(n=7) \\
\text { Side effects of surgery }{ }^{\S}(n=6)\end{array}$ & $\begin{array}{l}\text { Post -Sx Weight loss } \\
(n=12) \\
\text { Weight/health maintenance } \\
(n=9)\end{array}$ \\
\hline $\begin{array}{l}\text { Appraisal of the physical } \\
\text { and social self }\end{array}$ & $\begin{array}{l}\text { Lack of motivation }(\mathrm{n}=8) \\
\text { Lack of self-efficacy }(\mathrm{n}=9) \\
\text { Body dissatisfaction }(\mathrm{n}=11) \\
\text { Negative attitudes }(\mathrm{n}=5) \\
\text { Compromised psychological } \\
\text { health ( } \mathrm{n}=9) \\
\text { Lack of social support/active } \\
\text { relationships ( } \mathrm{n}=7) \\
\text { Competing responsibilities } \\
(\mathrm{n}=5)\end{array}$ & $\begin{array}{l}\text { Body image }(n=11) \\
\text { Enjoyment }(n=8) \\
\text { Social support/active } \\
\text { relationships }(n=10) \\
\text { Behavioural strategies }(n=5)\end{array}$ \\
\hline The exercise environment & $\begin{array}{l}\text { Lack of access to } \\
\text { accommodating } \\
\text { facilities/equipment }(n=7) \\
\text { Lack of access to exercise } \\
\text { knowledge }(n=7) \\
\text { Weather/climate }(n=6)\end{array}$ & 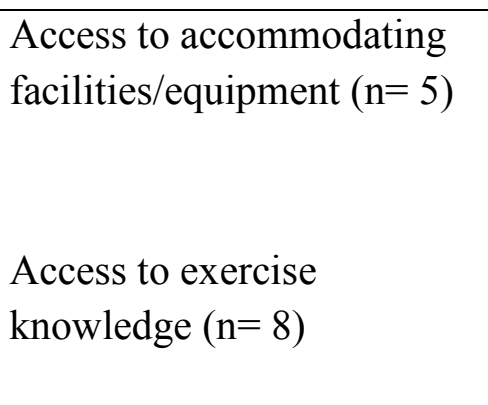 \\
\hline
\end{tabular}

$\S$ Barriers and facilitators/motivators that were cited exclusively in reference to the post-surgical period; $n=$ number of participants reported a given sub-theme (category). 


\section{Appendices}

\section{Appendix A: Interview Guide}

\section{Welcome:}

Thank you for taking the time to be here today. I really appreciate your willingness to participate. As you already know we are here today to discuss your past and present experiences with physical activity and exercise, before and after your surgery. We are hoping to use this information to help healthcare professionals develop ways to help people who have bariatric surgery become more physically active.

Please know that if at any point you wish to discontinue your participation in this interview, you may do so without reason and without any penalty. I really appreciate any insight you provide for me. And before we begin, I would like to mention a few things. First, whatever is said in this room stays here. Your privacy and confidentiality are very important to us. Secondly, I will be recording this conversation and then later transcribing it. However, I will never reveal your name in any of my work and you will remain anonymous. Is this okay with you?

Let's begin. :;

1) To start off, I was hoping you could tell me about some of your reasons for getting bariatric surgery.

2) How has surgery influenced your physical activity levels?

3) How soon after surgery did you start increasing your physical activity?

a. What helped you become more physically active?

4) Can you please tell me about some of the times in your life when you were regularly active?

a. What helped you stay physically active during those times?

b. What did you enjoy about being active then?

c. What were some things that you did not enjoy about being active?

5) Are you currently as active as you'd like to be?

a. If yes: What are some things that help you stay physically active?

b. If no: What are some things that are preventing you from being physically active?

We are almost done here, I just have a few more questions left for you.

6) We all have times in our lives when we are less physically active. Can you tell me a little bit about some of those times in your life? 
a. What prevented you from being physically active during these times?

b. What were some strategies that you have used to stay active?

7) We are working with physicians and surgeons to help patients with their physical activity challenges. Were you ever asked by your physician or surgeon to become more physically active?

a. If so, how did they ask you? How did you feel?

8) What role do you think healthcare professionals should play in helping individuals become more physically active?

9) Those are all of the questions I have for you today. Is there anything you'd like to add?

a. Do you have any questions for me?

Great, thank you very much for your time it has been a pleasure speaking with you! 


\section{Understanding Barriers to Physical Activity before and after Bariatric Surgery}

Researchers at McGill University are seeking to understand the challenges that severely overweight women have toward physical activity and exercise. If you are 18-70 years of age and have undergone Bariatric Surgery in the past 3-12 months (and up to 2 years), you may qualify to participate.

Participants will take part in a focus group and/or one individual interview that will ask about problems faced when starting and continuing an exercise program.

For more information, please call 514-476-3000 PI: Ross E. Andersen, Ph.D.

IRB Study Number A04-B09-12B

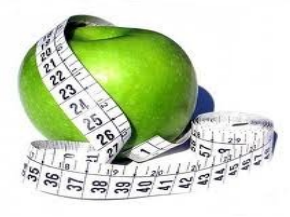

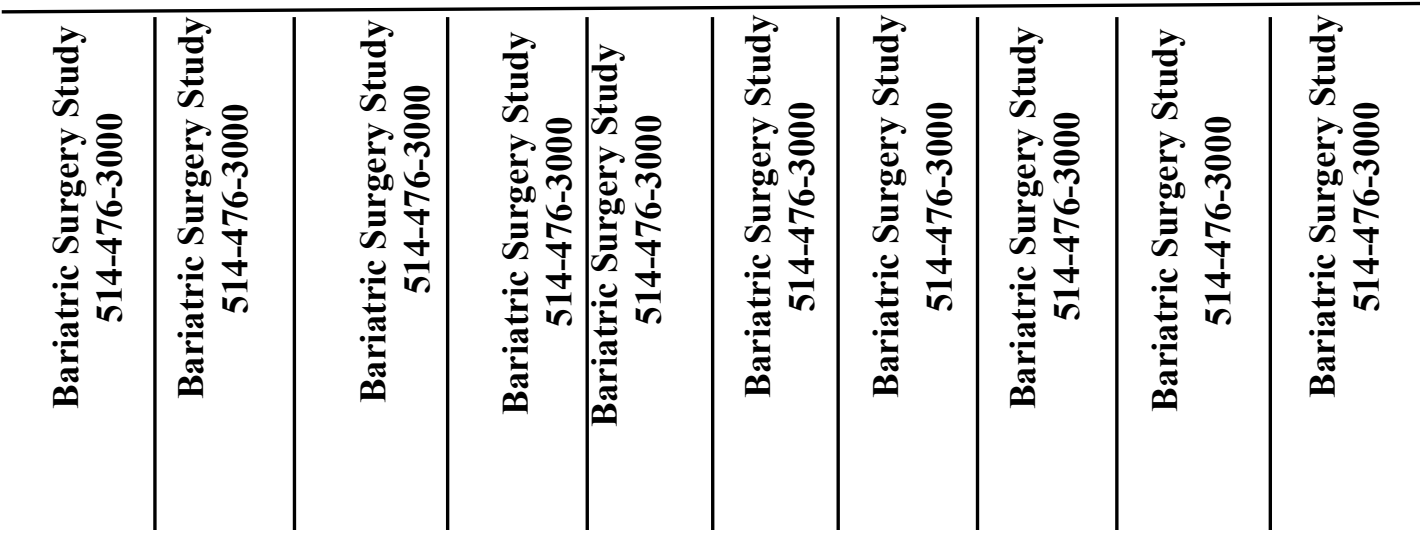




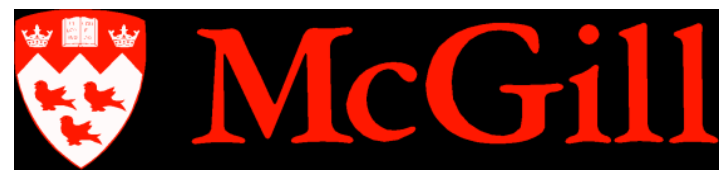

Department of Kinesiology Physical Education

475 Pine Avenue West

Montreal, Quebec

$\mathrm{H} 2 \mathrm{~W} 1 \mathrm{~S} 4$

Phone: 514-398-4184

\section{RESEARCH PARTICIPANT INFORMED CONSENT AND PRIVACY AUTHORIZATION FORM}

Protocol Title: $\quad$ Understanding Barriers to Physical Activity from the Obese Patient's Perspective

Sponsor: $\quad$ Unfunded

Principal Investigator: Ross Andersen, Ph.D.

Date:

January 15, 2013

Introduction:

- You are being asked to join a research study.

- This consent form explains the research study and your part in the study.

- Please read it carefully and take as much time as you need.

- Please ask questions at any time about anything you do not understand.

- You are a volunteer. If you join the study, you can change your mind later. You can decide not to take part or you can quit at any time. There will be no penalty or loss of benefits if you decide to quit the study. 
We may learn things during the study that might make you want to stop being in the study. If this happens, we will tell you about it. You can then decide if you want to stay in the study.

\section{Purpose of the Study}

This research is being done to help scientists understand the barriers that seriously overweight patients have toward physical activity and exercise. Better understanding of these issues will help health care professionals develop new strategies for overweight individuals to begin and stick with an exercise program. Approximately fifty people will be enrolled in this study.

\section{Procedures}

If you agree to take part in this study, a researcher will ask you to fill out a series of questionnaires about your physical activity patterns and quality of life, in addition to attending one focus group, and/or participating in one individual interview. The group will consist of 6-8 people who have recently had bariatric surgery. Dr. Susan Bartlett, a psychologist specializing in weight management, will lead the group with another member of the study staff. Individual interviews will be conducted by Dr. Bartlett and a study staff member as well. Regardless if you participate in a focus group, individual interview, or both, we will ask people in the group to think about the problems that they have with beginning and continuing an exercise program. Each focus group session or individual interview will last between 60-90 minutes. You may find some topics sensitive but you do not have to discuss anything that makes you feel uncomfortable or that you don't want to share with the group. You will be able to leave the room at any time you wish to do so. The group conversation and individual interview will be taped and transcribed; however, your identity will not be revealed in the transcripts. 
Focus group sessions will be conducted both in English and French.

\section{What are the risks or discomforts of the study?}

The risks of participating in this study are low. There are no physical risks associated with participation in the study. However, there is a risk of becoming tired, bored or feeling uncomfortable during the interview. You do not have to discuss anything that makes you feel uncomfortable.

You will be informed of any new findings during the course of this study that may influence your continued participation. If you feel that you have an illness or symptoms related to your participation in the study you should contact Dr. Ross Andersen at (514) 398-4184 ext 0482.

\section{Are there benefits to being in the study?}

There may be no direct benefit to you from participating in this study, although some overweight people may find it helpful to discuss health issues with others who are overweight. The information learned from this study may help scientists, health professionals and other care providers gain a better understanding of the challenges that seriously overweight people face in adopting more active lifestyles, which may result in improved patient care in the future.

\section{Voluntary Participation/Withdrawal}

Participation in this study is voluntary. You are free to refuse to participate, or to withdraw your consent to participate in this study at any time. Refusing to participate will involve no penalty or loss of benefits. 


\section{Will it cost you anything to be in this study?}

The study procedures will be provided at no cost to you.

\section{Compensation}

You will not receive any financial compensation for participating in this study.

In the event of injury as a result of your participation in this study, you will receive appropriate medical care under the Quebec Medicare or private insurance programs. Every effort to prevent injury that could result from your participation in this study will be taken by the investigator and study personnel.

You will be reimbursed for parking or public transportation costs.

\section{Confidentiality}

Hard copies of your test results will be stored in a locked file cabinet. The data will be entered into a computer database which will be accessible only through a password. Dr. Andersen and his students working on this project will be the only people with access to the data collected in this study. The tapes and questionnaires will be stored securely for five years after the scientific reports on this study are published. At this point, the hard copies of data will be shredded and the computer data bases will be erased.

The Institutional Review Board of the Faculty of Medicine may access the study data to ensure the sound management of the study. Every effort will be made to keep your medical information confidential. 
We will provide you with a detailed report about your current physical activity levels.

\section{Contact}

Please contact Dr. Ross Andersen at 514-398-4184 ext 0482 with any questions or concerns about this study.

You may contact Ms. Ilde Lepore, Senior Ethics Administrator, Institutional Review Board (514) 398-8302 for questions regarding participant rights.

\section{Participant consent}

My signature on this consent form means that the study has been explained to me, my questions have been answered to my satisfaction and I agree to participate fully in this study.

I do not waive my legal rights by signing this consent form.

\section{WE WILL GIVE YOU A COPY OF THIS SIGNED AND DATED CONSENT FORM}

Name of Participant (Please Print)

Signature of Participant

Date

Name of Person Obtaining Consent (Please Print)

Signature of Person Obtaining Consent

Date 
Appendix D: International Physical Activity Questionnaire-Short

\section{INTERNATIONAL PHYSICAL ACTIVITY QUESTIONNAIRE SHORT LAST 7 DAYS SELF-ADMINISTERED FORMAT}

FOR USE WITH YOUNG AND MIDDLE-AGED ADULTS (15-69 years)

INTERNATIONAL PHYSICAL ACTIVITY QUESTIONNAIRE

We are interested in finding out about the kinds of physical activities that people do as part of their everyday lives. The questions will ask you about the time you spent being physically active in the last 7 days. Please answer each question even if you do not consider yourself to be an active person. Please think about the activities you do at work, as part of your house and yard work, to get from place to place, and in your spare time for recreation, exercise or sport.

Think about all the vigorous activities that you did in the last 7 days.

Vigorous physical activities refer to activities that take hard physical effort and make you breathe much harder than normal. Think only about those physical activities that you did for at least 10 minutes at a time.

1. During the last $\mathbf{7}$ days, on how many days did you do vigorous physical activities like heavy lifting, digging, aerobics, or fast bicycling?

days per week

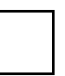

No vigorous physical activities Skip to question 3

2. How much time did you usually spend doing vigorous physical activities on one of those days?

hours per day minutes per day

$\square$ Don't know/Not sure 
Think about all the moderate activities that you did in the last 7 days.

Moderate activities refer to activities that take moderate physical effort and make you breathe somewhat harder than normal. Think only about those physical activities that you did for at least 10 minutes at a time.

3. During the last 7 days, on how many days did you do moderate physical activities like carrying light loads, bicycling at a regular pace, or doubles tennis? Do not include walking.

\section{days per week}

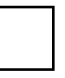

No moderate physical activities

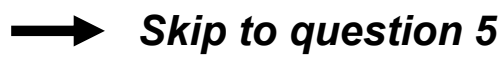

4. How much time did you usually spend doing moderate physical activities on one of those days?

hours per day minutes per day

$\square$ Don't know/Not sure

Think about the time you spent walking in the last 7 days. This includes at work and at home, walking to travel from place to place, and any other walking that you might do solely for recreation, sport, exercise, or leisure.

5. During the last $\mathbf{7}$ days, on how many days did you walk for at least 10 minutes at a time?

days per week

No walking $\longrightarrow$ Skip to question 7 
6. How much time did you usually spend walking on one of those days? hours per day minutes per day

$\square$ Don't know/Not sure

The last question is about the time you spent sitting on weekdays during the last 7 days. Include time spent at work, at home, while doing course work and during leisure time. This may include time spent sitting at a desk, visiting friends, reading, or sitting or lying down to watch television.

7. During the last $\mathbf{7}$ days, how much time did you spend sitting on a week day?

hours per day
minutes per day
$\square$ Don't know/Not sure

This is the end of the questionnaire, thank you for participating. 


\title{
Appendix E: Impact of Weight on Quality of Life-Lite Questionnaire
}

\author{
Impact of Weight on Quality of Life Questionnaire-Lite Version (IWQOL-Lite)
}

Please answer the following statements by circling the number that best applies to you in the past week. Be as open as possible. There are no right or wrong answers.

\begin{tabular}{|c|c|c|c|c|c|c|}
\hline \multicolumn{2}{|c|}{ Physical Function } & $\begin{array}{l}\text { ALWAYS } \\
\text { TRUE }\end{array}$ & $\begin{array}{l}\text { USUALLY } \\
\text { TRUE }\end{array}$ & $\begin{array}{l}\text { SOMETIMES } \\
\text { TRUE }\end{array}$ & $\begin{array}{l}\text { RARELY } \\
\text { TRUE }\end{array}$ & $\begin{array}{l}\text { NEVER } \\
\text { TRUE }\end{array}$ \\
\hline 1. & $\begin{array}{l}\text { Because of my weight I have trouble } \\
\text { picking up objects. }\end{array}$ & 5 & 4 & 3 & 2 & 1 \\
\hline 2. & $\begin{array}{l}\text { Because of my weight I have trouble tying } \\
\text { my shoes. }\end{array}$ & 5 & 4 & 3 & 2 & 1 \\
\hline 3. & $\begin{array}{l}\text { Because of my weight I have difficulty } \\
\text { getting up from chairs. }\end{array}$ & 5 & 4 & 3 & 2 & 1 \\
\hline 4. & $\begin{array}{l}\text { Because of my weight I have trouble using } \\
\text { stairs. }\end{array}$ & 5 & 4 & 3 & 2 & 1 \\
\hline 5. & $\begin{array}{l}\text { Because of my weight I have difficulty } \\
\text { putting on or taking off my clothing. }\end{array}$ & 5 & 4 & 3 & 2 & 1 \\
\hline 6. & $\begin{array}{l}\text { Because of my weight I have trouble with } \\
\text { mobility. }\end{array}$ & 5 & 4 & 3 & 2 & 1 \\
\hline 7. & $\begin{array}{l}\text { Because of my weight I have trouble } \\
\text { crossing my legs. }\end{array}$ & 5 & 4 & 3 & 2 & 1 \\
\hline 8. & I feel short of breath with only mild exertion. & 5 & 4 & 3 & 2 & 1 \\
\hline 9. & I am troubled by painful or stiff joints. & 5 & 4 & 3 & 2 & 1 \\
\hline 10. & $\begin{array}{l}\text { My ankles and lower legs are swollen at } \\
\text { the end of the day. }\end{array}$ & 5 & 4 & 3 & 2 & 1 \\
\hline 11. & I am worried about my health. & 5 & 4 & 3 & 2 & 1 \\
\hline \multicolumn{2}{|c|}{ Self-esteem } & $\begin{array}{l}\text { ALWAYS } \\
\text { TRUE }\end{array}$ & $\begin{array}{l}\text { USUALLY } \\
\text { TRUE }\end{array}$ & $\begin{array}{l}\text { SOMETIMES } \\
\text { TRUE }\end{array}$ & $\begin{array}{l}\text { RARELY } \\
\text { TRUE }\end{array}$ & $\begin{array}{l}\text { NEVER } \\
\text { TRUE }\end{array}$ \\
\hline 1. & Because of my weight I am self-conscious. & 5 & 4 & 3 & 2 & 1 \\
\hline 2. & $\begin{array}{l}\text { Because of my weight my self-esteem is } \\
\text { not what it could be. }\end{array}$ & 5 & 4 & 3 & 2 & 1 \\
\hline 3. & $\begin{array}{l}\text { Because of my weight I feel unsure of } \\
\text { myself. }\end{array}$ & 5 & 4 & 3 & 2 & 1 \\
\hline 4. & Because of my weight I don't like myself. & 5 & 4 & 3 & 2 & 1 \\
\hline 5. & $\begin{array}{l}\text { Because of my weight I am afraid of being } \\
\text { rejected. }\end{array}$ & 5 & 4 & 3 & 2 & 1 \\
\hline 6. & $\begin{array}{l}\text { Because of my weight I avoid looking in } \\
\text { mirrors or seeing myself in photographs. }\end{array}$ & 5 & 4 & 3 & 2 & 1 \\
\hline 7. & $\begin{array}{l}\text { Because of my weight I am embarrassed to } \\
\text { be seen in public places. }\end{array}$ & 5 & 4 & 3 & 2 & 1 \\
\hline
\end{tabular}




\begin{tabular}{|l|l|c|c|c|c|c|}
\hline Sexual Life & $\begin{array}{c}\text { ALWAYS } \\
\text { TRUE }\end{array}$ & $\begin{array}{c}\text { USUALLY } \\
\text { TRUE }\end{array}$ & $\begin{array}{c}\text { SOMETIMES } \\
\text { TRUE }\end{array}$ & $\begin{array}{c}\text { RARELY } \\
\text { TRUE }\end{array}$ & $\begin{array}{c}\text { NEVER } \\
\text { TRUE }\end{array}$ \\
\hline 1. & $\begin{array}{l}\text { Because of my weight I do not enjoy sexual } \\
\text { activity. }\end{array}$ & 5 & 4 & 3 & 2 & 1 \\
\hline 2. & $\begin{array}{l}\text { Because of my weight I have little or no } \\
\text { sexual desire. }\end{array}$ & 5 & 4 & 3 & 2 & 1 \\
\hline 3. & $\begin{array}{l}\text { Because of my weight I have difficulty with } \\
\text { sexual performance. }\end{array}$ & 5 & 4 & 3 & 2 & 1 \\
\hline 4. & $\begin{array}{l}\text { Because of my weight I avoid sexual } \\
\text { encounters whenever possible. }\end{array}$ & 5 & 4 & 3 & 2 & 1 \\
\hline
\end{tabular}

\begin{tabular}{|l|l|c|c|c|c|c|}
\hline \multicolumn{2}{|l|}{ Public Distress } & $\begin{array}{c}\text { ALWAYS } \\
\text { TRUE }\end{array}$ & $\begin{array}{c}\text { USUALLY } \\
\text { TRUE }\end{array}$ & $\begin{array}{c}\text { SOMETIMES } \\
\text { TRUE }\end{array}$ & $\begin{array}{c}\text { RARELY } \\
\text { TRUE }\end{array}$ & $\begin{array}{c}\text { NEVER } \\
\text { TRUE }\end{array}$ \\
\hline 1. & $\begin{array}{l}\text { Because of my weight I experience ridicule, } \\
\text { teasing, or unwanted attention. }\end{array}$ & 5 & 4 & 3 & 2 & 1 \\
\hline 2. & $\begin{array}{l}\text { Because of my weight I worry about fitting } \\
\text { into seats in public places (e.g. theaters, } \\
\text { restaurants, cars, or airplanes). }\end{array}$ & 5 & 4 & 3 & 2 & 1 \\
\hline 3. & $\begin{array}{l}\text { Because of my weight I worry about fitting } \\
\text { through aisles or turnstiles. }\end{array}$ & 5 & 4 & 3 & 2 & 1 \\
\hline 4. & $\begin{array}{l}\text { Because of my weight I worry about finding } \\
\text { chairs that are strong enough to hold my } \\
\text { weight. }\end{array}$ & 5 & 4 & 3 & 2 & 1 \\
\hline 5. & $\begin{array}{l}\text { Because of my weight I experience } \\
\text { discrimination by others. }\end{array}$ & 5 & 4 & 3 & 2 & 1 \\
\hline Work (Note: For homemakers and \\
\hline
\end{tabular}

